\title{
Learning by Doing, Precommitment and Infant-Industry Promotion
}

\author{
DERMOT LEAHY and J. PETER NEARY \\ University College Dublin
}

First version received December 1995; final version accepted December 1997 (Eds.)

\begin{abstract}
We examine the implications for strategic trade policy of different assumptions about precommitment in a two-period Cournot oligopoly game with learning by doing. The inability of firms and governments to precommit to future actions encourages strategic behaviour which justifies an optimal first-period export tax relative to the profit-shifting benchmark of an export subsidy. In the linear case the optimal subsidy is increasing in the rate of learning with government precommitment but decreasing in it without, in apparent contradiction to the infant-industry argument. Extensions to active foreign policy, distortionary taxation and Bertrand competition are also considered.
\end{abstract}

\section{INTRODUCTION}

The central theme in strategic trade policy is that a government's ability to precommit to tariffs or subsidies may make intervention desirable in oligopolistic markets. ${ }^{1}$ An important theme in industrial organization is that a firm's ability to precommit to future actions gives it an incentive to behave strategically. ${ }^{2}$ In this paper we make a start at integrating these insights and show that the implications are dramatic. In the model we consider, strategic behaviour by firms typically reduces and may even reverse the government's incentive to offer a strategic trade policy. ${ }^{3}$

The specific context in which we explore the issues of precommitment and strategic behaviour is that of learning by doing. ${ }^{4}$ Our model builds on that of Fudenberg and Tirole (1983). They compared equilibria in which oligopolistic firms can precommit to future outputs with equilibria in which they cannot. ${ }^{5}$ However, in discussing government policies,

1. See, for example, Dixit (1984), Brander and Spencer (1985) and Eaton and Grossman (1986).

2. By strategic behaviour we mean behaviour which is not optimal in a static context but which changes the future behaviour of other agents to the firm's advantage. See, for example, Spence (1977) and Dixit (1980) for strategic choice of capacity, Fudenberg and Tirole (1983) for experience as a strategic variable and Fudenberg and Tirole (1984) for an overview.

3. Aspects of precommitment in trade policy have been studied by Eaton and Grossman (1985), Staiger and Tabellini (1987), Lapan (1988) and Matsuyama (1990). A paper which is closer to ours is Maskin and Newbery (1990), who compare optimal tariffs for the importer of a natural resource with and without precommitment. A recent paper by Goldberg (1995) looks at similar issues in a model with R\&D. Unlike our model, her firms' objective functions are not differentiable in their decision variables, so her results are not directly comparable with ours.

4. From the pioneering work of Arrow (1962) to recent work on endogenous growth theory (e.g. Grossman and Helpman (1991) and Young (1991)), learning by doing has long been recognized as a phenomenon of theoretical and empirical importance.

5. Fudenberg and Tirole's work drew on Spence (1981), who claimed that the qualitative differences between these two equilibria were only minor. However, Bulow et al. (1985) showed that this result derived from the functional forms used by Spence. 
Fudenberg and Tirole assumed without discussion that the government can precommit to future policies. Such long-term precommitment is not especially plausible. Moreover, as first noted by Leahy (1992), if the government cannot precommit, then a firm which enjoys learning by doing has an incentive to play strategically against it. A forward-looking government in turn will anticipate this behaviour and take it into account in determining its optimal policy towards the firm in its learning phase.

From a trade policy perspective, learning by doing is often cited as a justification for intervention, especially to assist infant industries, although in a competitive environment this argument requires some additional distortion such as capital-market imperfections or externalities. ${ }^{6}$ However, the literature on strategic trade policy in imperfectly competitive markets has shown that shifting profits from foreign to home firms may justify intervention even in the absence of learning by doing. This raises the question of whether learning by doing strengthens the case for strategic trade policy. To investigate this, we incorporate dynamic elements into a model of strategic export subsidization due to Brander and Spencer (1985) by allowing for the effects of current output on future costs.

The plan of the paper is as follows. Section 2 sketches the model and introduces the different assumptions about precommitment which are explored in the paper. Section 3 considers the benchmark case where the home government and both firms precommit in period 1 to outputs and subsidy levels in period 2. These assumptions are then relaxed in Sections 4 and 5, which consider in turn the effects of ruling out precommitment by firms and by government. Section 6 shows how the results are strengthened in two special cases: where the foreign firm does not benefit from learning by doing and where the demand and learning functions are linear. Section 7 considers a number of extensions, allowing for an active foreign government, a non-unitary social cost of funds and price rather than quantity competition. Finally, Section 8 concludes with a summary of the paper's results and a discussion of the implications for the infant-industry argument and for the general principles guiding government policy in dynamic environments.

\section{THE MODEL}

The model to be used in most of the paper builds on the Brander-Spencer (1985) export subsidy model, extending it to two periods which are linked by learning by doing. ${ }^{7}$ There are two firms, a home firm producing output levels $x_{1}$ and $x_{2}$ in periods 1 and 2 respectively and a foreign firm producing output levels $y_{1}$ and $y_{2}$. Outputs are homogeneous in each period and both firms face the same inverse demand functions

$$
p_{i}=p_{i}\left(x_{i}+y_{i}\right), \quad i=1,2 ; \quad p_{i}^{\prime} \equiv-b_{i}<0 .
$$

We denote by $R^{i}=p_{i} x_{i}$ the home firm's sales revenue in period $i$, with $R_{y}^{i}<0$. A symmetric specification applies to the foreign firm's revenue function $R^{* i}=p_{i} y_{i}$.

6. Baldwin (1969) summarizes these arguments; Bardhan (1970), Clemhout and Wan (1970), van Wijnbergen (1984) and Krugman (1987) consider the implications of production externalities; Grossman and Horn (1988) explore the role of informational asymmetries; and Flam and Staiger (1991) and Bond (1993) model capital-market imperfections. In this paper home firms export all their output so we focus on infant-industry promotion rather than protection but the model is easily extended to allow for home consumption and tariffs as well as subsidies.

7. Earlier studies of learning by doing and strategic trade policy include Krugman (1984), Baldwin and Krugman (1988) and Gatsios (1989). These papers assumed that governments can precommit to future policies. Leahy (1992) relaxed this assumption and explored the implications of firms playing strategically against governments. Neary (1994, Section 4) extended this model to the case where the government anticipates the firms' actions. The latter two papers followed Fudenberg and Tirole in considering strategic effects of learning in linear examples only. 
Firms produce with constant marginal costs in each period but benefit from learning by doing between periods. Thus, the home firm has a given marginal cost, $c_{1}$, in the first, learning, period whereas its marginal cost in the second period, $c_{2}$, depends negatively on its output in period 1 and on a shift parameter, $\varepsilon$

$$
c_{2}=c_{2}\left(x_{-}, \varepsilon\right), \quad \frac{\partial c_{2}}{\partial x_{1}} \equiv-\lambda\left(x_{1}, \varepsilon\right) \leqq 0,
$$

where the signs indicate the signs of the corresponding partial derivatives. Here $\lambda$ measures the rate of learning and is increasing in $\varepsilon: \lambda_{\varepsilon}>0$. A symmetric specification, with corresponding parameters $\lambda^{*}$ and $\varepsilon^{*}$, applies to the foreign firm.

Each firm seeks to maximize the present value of its profits in the two periods, with future profits discounted by a factor $\rho$. Thus, for the home firm: $\pi=\pi_{1}+\rho \pi_{2}$, where profits in each period equal revenue $R^{i}$ less production costs plus subsidies

$$
\pi_{i}=R^{i}-\left(c_{i}-s_{i}\right) x_{i}=\left(p_{i}-c_{i}+s_{i}\right) x_{i}, \quad i=1,2 .
$$

(Fixed costs are ignored for simplicity since the important issues relating to entry and exit of firms from the market are not considered in the paper.) Until Section 7.1, we assume that subsidies are provided by the home government only, which seeks to maximize the present value of welfare. For reasons to be discussed, welfare in each period equals profits net of subsidy payments, so its present value is

$$
W=R^{1}-c_{1} x_{1}+\rho\left(R^{2}-c_{2} x_{2}\right)
$$

This can also be written as $W=W_{1}+\rho W_{2}$, where $W_{i}=\pi_{i}-s_{i} x_{t}=\left(p_{t}-c_{i}\right) x_{i}, i=1,2$. Totally differentiating (4) gives a useful expression for the change in welfare which applies in all the equilibria we consider

$$
d W=\left(R_{x}^{1}-c_{1}+\rho \lambda x_{2}\right) d x_{1}+R_{y}^{1} d y_{1}+\rho\left(R_{x}^{2}-c_{2}\right) d x_{2}+\rho R_{y}^{2} d y_{2} .
$$

Two alternative rationales can be given for the welfare function (4). Following Brander and Spencer (1985), we may assume that there is no home consumption, so both firms export all their output to a third market. Alternatively, we may assume that the firms sell into each others' markets facing a common price in each period given by (1) and that the government attaches zero weight to consumers. In either case, the marginal social cost of funds is unity, an assumption which we relax in Section 7.2.

A key feature of our model is the order of moves by different agents. We follow Brander and Spencer throughout in two crucial respects. First (except in Section 7.3), we assume that firms are Cournot competitors, making simultaneous, noncooperative decisions about their output levels in each period. Second, we assume that in each period the government can credibly precommit to a subsidy before outputs are chosen. ${ }^{8}$ The government thus has the ability to precommit intratemporally in all cases. However, different assumptions about intertemporal precommitment are possible. Depending on the assumptions made we can distinguish three different types of equilibrium:

Full Precommitment Equilibrium (FCE). In this two-stage game, all agents take decisions for both periods at the beginning of period 1. Thus, in the first stage of the game, the government chooses the subsidies $s_{1}$ and $s_{2}$, and in the second stage the two firms choose both their present and future outputs noncooperatively.

8. The implications of reversing the intratemporal order of moves by government and firms in a static export subsidy game have been considered by Carmichael (1987), Gruenspecht (1988) and Neary (1991 and 1994, Section 5). 
Government-Only Precommitment Equilibrium (GCE). In this three-stage game the government can precommit in period 1 to its second-period action but the firms cannot. Thus the first stage is the same as in FCE; in the second stage the firms choose their period-1 outputs; and in the third stage they choose their period-2 outputs. (The two cases of FCE and GCE correspond to the equilibria compared by Spence (1981) and Fudenberg and Tirole (1983) and are often called "open-loop" and "closed-loop" respectively. This terminology is less appropriate here, since there are two types of agents, governments and firms.)

Sequence Equilibrium (SE). The final case is a four-stage game, in which no agents can precommit to future actions. In each period, the government first sets the subsidy and the firms then choose their outputs.'

Throughout the paper, we assume that all the equilibria considered are subgame perfect, in the sense of Selten (1965). All agents thus take account of the influence of their current actions on the future actions of other agents and it is this forward-looking behaviour which opens up the possibility of agents playing strategically. Different move orders imply different strategic incentives for the home firm and the home government. The key issue we address is how government policy takes account of the different strategic possibilities open to the home firm.

\section{OPTIMAL SUBSIDIES WITH FULL PRECOMMITMENT}

We consider first the benchmark case of FCE. The home firm seeks to maximize the present value of profits, given by

$$
\pi=\pi_{+\neq-}\left(x_{1}, y_{1}, s_{1}\right)+\rho \pi_{+}\left[x_{+}, y_{2}, c_{-}\left(x_{-}, \varepsilon\right),+s_{+}\right],
$$

where the signs indicate the signs of the corresponding partial derivatives. Optimal choice of second-period output sets the partial derivative of $\pi_{2}$ with respect to $x_{2}$ equal to zero, yielding a standard first-order condition, with marginal revenue (including the subsidy) less marginal cost equal to zero

$$
R_{x}^{2}-c_{2}+s_{2}=0 .
$$

The firm's choice of output in the first period is more complex, since it must take account of the effects on profits in both periods. In FCE, it takes the foreign firm's outputs and the subsidy levels in both periods as given. There remains the pure (non-strategic) learning-bydoing effect, whereby the home firm's choice of $x_{1}$ affects its future costs $c_{2}$. Differentiating $\pi$ with respect to $x_{1}$ and using equation (2) and the fact that $\partial \pi_{2} / \partial c_{2}$ equals $-x_{2}$ gives

$$
\frac{d \pi}{d x_{1}}=\frac{\partial \pi_{1}}{\partial x_{1}}+\rho \frac{\partial \pi_{2}}{\partial c_{2}} \frac{d c_{2}}{d x_{1}}=R_{x}^{1}-c_{1}+s_{1}+\rho \lambda x_{2}=0 .
$$

This implies that marginal revenue is set below marginal cost in the first period $\left(R_{x}^{1}-c_{1}+s_{1}\right.$ is negative). The home firm has an incentive to produce beyond the point of

9. We use the term "sequence equilibrium" rather than the more natural "sequential equilibrium" since the latter is used differently by Kreps and Wilson (1982) to refer to finite games in which players' strategies are sequentially rational. Since all the equilibria we consider are perfect in the sense of Selten (1965), it follows from Proposition 5 of Kreps and Wilson that all our equilibria are sequential in their sense. 
short-run profit maximization in order to learn faster and bring down its costs in period 2.

What is the optimal policy for the government, anticipating this behaviour? Since the home firm fully internalizes the gains from learning and, in FCE, does not behave strategically, there is no basis for intervention other than that which arises in the static BranderSpencer model. The only role for the government is to use its superior precommitment ability to offer subsidies to the home firm which shift profits towards it and away from the foreign firm. Substituting from the home firm's first-order conditions (7) and (8) into the expression for welfare change (5) gives

$$
d W=-\left(s_{1} d x_{1}-R_{y}^{1} d y_{1}\right)-\rho\left(s_{2} d x_{2}-R_{y}^{2} d y_{2}\right) .
$$

To eliminate the changes in $y_{1}$ and $y_{2}$, the home government solves the foreign firm's firstorder conditions, which, except for the absence of subsidies, are identical to those of the home firm

$$
\begin{array}{r}
\frac{d \pi^{*}}{d y_{1}}=R_{1}^{* 1}-c_{1}^{*}+\rho \lambda^{*} y_{2}=0, \\
\rho^{-1} \frac{d \pi^{*}}{d y_{2}}=R_{3}^{* 2}-c_{2}^{*}=0 .
\end{array}
$$

Solving these gives (in differential form) the two-period reaction functions of the foreign firm, which show how each of its outputs responds to changes in both of the home firm's

$$
\begin{aligned}
& d y_{1}=Y_{11}^{F} d x_{1}+Y_{12}^{F} d x_{2}, \\
& d y_{2}=Y_{21}^{F} d x_{1}+Y_{22}^{F} d x_{2} .
\end{aligned}
$$

Substituting from these into (9) expresses the change in welfare in terms of changes in home outputs only, which are fully determined by the two instruments $s_{1}$ and $s_{2}$. Hence, setting the coefficients of $d x_{1}$ and $d x_{2}$ equal to zero gives the optimal subsidies

$$
\begin{aligned}
& s_{1}^{F}=R_{1}^{1} Y_{11}^{F}+\rho R_{1}^{2} Y_{21}^{F}, \\
& s_{2}^{F}=\rho^{-1} R_{1}^{1} Y_{12}^{F}+R_{y}^{2} Y_{22}^{F} .
\end{aligned}
$$

We show in the Appendix that the within-period coefficients $Y_{i i}^{F}, i=1,2$, are negative if and only if foreign output is a strategic substitute for home output in period $i$, meaning that the marginal profitability of $y_{i}$ is decreasing in $x_{i}: \pi_{y_{i} x_{i}}<0$. (See Bulow et al. (1985).) Similarly the between-period coefficients $Y_{i j}^{F}, i \neq j, i=1,2$, are negative if and only if foreign output is a strategic substitute for home output in period $j$ and there is some foreign learning $\left(\lambda^{*}>0\right)$. Summarizing:

Proposition 1. In FCE, the optimal subsidies in each period are positive provided foreign output is a strategic substitute for home output in both periods.

To interpret these subsidies, note that if there were no foreign learning the betweenperiod terms $Y_{12}^{F}$ and $Y_{21}^{F}$ vanish and both subsidies collapse to the standard formula for the Brander-Spencer case: $s_{i}^{F}=R_{y}^{i} Y_{i i}^{F}, i=1,2$. The between-period terms $Y_{12}^{F}$ and $Y_{21}^{F}$ represent intertemporal rent-shifting in addition to the standard intratemporal type.

Notwithstanding these additional complications, the motive for intervention is the same as in the static model: the government uses its superior commitment power to bring about the equilibrium which would obtain if the home firm were a Stackelberg leader, 
choosing $x_{1}$ and $x_{2}$ before $y_{1}$ and $y_{2}$. The government's actions move the home firm to the optimal position on the foreign firm's two-period reaction functions.

\section{OPTIMAL SUBSIDIES WHEN ONLY THE GOVERNMENT CAN PRECOMMIT}

How are the conclusions of the previous section affected when the government can still precommit to a future subsidy but firms cannot precommit in period 1 to their period-2 outputs? Equations (7) and (11), giving the first-order conditions for the home and foreign firms respectively in the second period, are unaffected. However, as Fudenberg and Tirole (1983) emphasized, each firm now has an additional strategic incentive to increase its output in the first period. Not only will the resulting fall in second-period costs raise its future profits directly, but it will also improve its future strategic position in competition with the rival firm. The home firm therefore chooses $x_{1}$ to maximize profits (6), recognizing its influence on the foreign firm's future output $y_{2}$ (with $\partial \pi_{2} / \partial y_{2}=R_{y}^{2}<0$ ). This yields a new period-1 first-order condition

$$
\frac{d \pi}{d x_{1}}=\frac{\partial \pi_{1}}{\partial x_{1}}+\rho\left\{\frac{\partial \pi_{2}}{\partial c_{2}} \frac{d c_{2}}{d x_{1}}+\frac{\partial \pi_{2}}{\partial y_{2}} \frac{d y_{2}}{d x_{1}}\right\}=R_{x}^{1}-c_{1}+s_{1}+\rho\left\{\lambda x_{2}+R_{y}^{2} \frac{d y_{2}}{d x_{1}}\right\}=0 .
$$

We show in the Appendix that the strategic effect $d y_{2} / d x_{1}$ is negative if and only if $y_{2}$ is a strategic substitute for $x_{2}$. Given this, the home firm has an even greater incentive to produce beyond the point of short-run profit maximization than in FCE. (Compare (8).) The foreign firm faces similar incentives, since its period-1 first-order condition is now

$$
\frac{d \pi^{*}}{d y_{1}}=R_{y}^{* 1}-c_{1}^{*}+\rho\left\{\lambda^{*} y_{2}+R_{x}^{* 2} \frac{d x_{2}}{d y_{1}}\right\}=0 .
$$

In the terminology of Fudenberg and Tirole (1984), both firms behave like "top dogs", "over-producing" in period 1 to obtain a strategic advantage in the period-2 game.

Of course, the actual levels of output chosen by the firms depend on the subsidies which, as in FCE, are chosen by the government in the first stage of the game. As in the last section, the optimal subsidies are found by substituting from the home firm's firstorder conditions into the expression for welfare change (5)

$$
d W=-\left\{s_{1}+\rho R_{y}^{2} \frac{d y_{2}}{d x_{1}}\right\} d x_{1}+R_{y}^{1} d y_{1}-\rho\left(s_{2} d x_{2}-R_{y}^{2} d y_{2}\right) .
$$

As before, the government calculates the slopes of the foreign firm's reaction functions by solving its two first-order conditions, (17) and (11), for $d y_{1}$ and $d y_{2}$. Using $Y_{i j}^{G}(i, j=1,2)$ to denote the response of $y_{i}$ to $x_{j}$ in this game, and substituting into (18) yields the optimal subsidies

$$
\begin{aligned}
& s_{1}^{G}=R_{y}^{1} Y_{11}^{G}+\rho R_{y}^{2} Y_{21}^{G}-\rho R_{y}^{2} \frac{d y_{2}}{d x_{1}}, \\
& s_{2}^{G}=\rho^{-1} R_{y}^{1} Y_{12}^{G}+R_{y}^{2} Y_{22}^{G} .
\end{aligned}
$$

Comparing these with the optimal subsidies in FCE, (14) and (15), the rent-shifting terms are different and there is an additional term in the expression for the period-1 subsidy.

As far as the first of these differences is concerned, it arises solely from the presence of the strategic term $d x_{2} / d y_{1}$ in the foreign firm's period-1 first-order condition (17). 
Because of this term the reaction function slopes $Y_{i j}^{G}$ are considerably more complex than in the FCE case. In particular, a change in $s_{2}$ now has a direct effect on the foreign firm, by affecting the magnitude of the strategic effect $d x_{2} / d y_{1}$, in addition to the usual indirect effects which work by altering home outputs. The details of these complications are given in the Appendix, where it is shown that the $Y_{i j}^{G}$ coefficients cannot be unambiguously signed. Nevertheless, there is a presumption that they are all negative provided foreign output is a strategic substitute for home output in both periods. In any case, it is clear that the motive for intervention underlying these terms is the standard rent-shifting one.

By contrast, the final term in expression (19) for $s_{1}^{G}$ is new. Referring back to (16), it can be seen that it exactly offsets the strategic effect in the home firm's period-1 firstorder condition and so is negative provided $y_{2}$ is a strategic substitute for $x_{2}$. In that case, the government provides a lower subsidy in the first period relative to the profit-shifting benchmark, in order to restrain the home firm from "over-producing" strategically in an attempt to drive down the foreign firm's output next period. Intuitively, left to itself the home firm produces more in period 1 in order to commit itself to a higher output in period 2. But this incurs a social cost, since period-1 output exceeds the efficient level. By contrast, the government is able to use its first-mover advantage to commit the firm to higher output at zero social cost (given the assumption that the marginal social cost of funds is unity) ${ }^{10}$ It is for this reason that, relative to the profit-shifting benchmark, the optimal period-1 subsidy exactly offsets the strategic term in the home firm's first-order condition. This result is similar to that of Spencer and Brander (1983), who considered a model similar to ours in which firms engaged in cost-reducing R\&D rather than producing output in period 1 . They found that the optimal policy package was an output subsidy in period 2 coupled with an R\&D tax in period 1 . In their case the profit-shifting benchmark was zero, since the firms did not compete directly in the first period.

Summarizing the results of this section:

Proposition 2. In GCE, the optimal subsidies have the same form as in FCE, except that the expression for $s_{1}$ contains an extra term which exactly offsets the strategic behaviour by the home firm.

\section{OPTIMAL SUBSIDIES IN SEQUENCE EQUILIBRIUM}

Sections 3 and 4 have examined optimal intervention in the cases of precommitment and sequential decision-making by firms. In this section we break new ground by considering the case where neither the government nor the firms can precommit intertemporally. For the first time, this implies that government policy is partly endogenous.

Consider first the second period. This is a standard two-stage Brander-Spencer game in which, with production costs predetermined, the government first sets $s_{2}$ to maximize $W_{2}$ and the two firms then choose outputs to maximize profits. The firms' first-order conditions are standard, given by (7) and (11). Maximizing second-period welfare subject to them leads to the familiar Brander-Spencer formula

$$
s_{2}^{\mathrm{S}}=R_{y}^{2} \psi_{x},
$$

where $\psi_{x}$ is the slope of the foreign firm's period-2 reaction function obtained by solving its first-order condition (11): $y_{2}=\psi\left(x_{2} ; y_{1}\right)$. As in Brander and Spencer (1985), $s_{2}^{s}$ is positive if and only if $y_{2}$ is a strategic substitute for $x_{2}$.

10. We are grateful to a referee for suggesting this intuition. 
The new feature is that the government's choice of $s_{2}$ is conditional on the firms' prior choice of $x_{1}$ and $y_{1}$. Using the two period-2 first-order conditions to eliminate $x_{2}$ and $y_{2}$ from the right-hand side of (21) gives a reduced-form expression for the period-2 optimal subsidy: $s_{2}^{S}=\Psi\left(x_{1}, y_{1}\right)$. The $\Psi$ notation highlights the fact that the government's choice of $s_{2}$ is a movement along a reaction function. The restrictions on the derivatives of $\Psi$ are derived in the Appendix. In particular, we show there that the condition for $\Psi_{x}$ to be positive, implying that $s_{2}$ is a strategic complement for $x_{1}$, is

$$
\Psi_{x} \equiv \frac{d s_{2}^{S}}{d x_{1}}>0 \quad \text { iff } \quad 1+\mu_{2}+\alpha_{2} r_{2}\left(1+\psi_{x}\right)>0 .
$$

Here $\alpha_{2}$ is the home firm's market share, $x_{2} /\left(x_{2}+y_{2}\right) ; r_{2}$ equals $\left(x_{2}+y_{2}\right) b_{2}^{\prime} / b_{2}$, a measure of the concavity of the demand function; and $\mu_{2}$ equals $x_{2} \psi_{x x} / \psi_{x}$, a measure of the concavity of the foreign firm's reaction function. The foreign firm's second-order condition implies that $1+\psi_{x}$ must be positive and it must be less than unity if $y_{2}$ is a strategic substitute for $x_{2}$. When demands are linear the expression in (22) equals unity, and with general demands a sufficient condition for it to be positive is that both $r_{2}$ and $\mu_{2}$ are nonnegative. Summarizing:

Proposition 3. $\Psi_{x}$ is positive, and so the optimal subsidy in period 2 of a SE is a strategic complement for $x_{1}$, if and only if the expression in (22) is positive. A sufficient condition for this is that neither the demand curve nor the foreign firm's reaction function in period 2 is "too" convex.

This result generalizes those of de Meza (1986) and Neary (1994). They considered a static Brander-Spencer game and derived sufficient conditions for a fall in the home firm's marginal cost to raise the optimal subsidy. Equation (22) gives a necessary and sufficient condition for an increase in period-1 output, which lowers period-2 costs, to mandate a higher subsidy.

Consider next the behaviour of agents in the first period. Unlike the equilibria considered in previous sections, each firm now plays strategically against the home government as well as against its rival. The first-order condition for the home firm is

$$
R_{x}^{1}-c_{1}+s_{1}+\rho\left\{\lambda x_{2}+R_{y}^{2} \frac{d y_{2}}{d x_{1}}+x_{2} \Psi_{x}\right\}=0
$$

Comparing this with the corresponding formula in the GCE case, (16), we see that the home firm has an additional incentive to increase output in the first period, provided the future subsidy is a strategic complement for first-period output. As for the foreign firm, its period-1 first-order condition is identical in form to (16) in GCE. Of course, the interfirm strategic terms in both firms' first-order conditions $\left(d y_{2} / d x_{2}\right.$ for the home firm and $d x_{2} / d y_{2}$ for the foreign firm) differ from those in GCE, since they incorporate the dependence of $s_{2}$ on $x_{1}$ and $y_{1}$.

The final step is to consider the government's optimization problem in the first stage of the game. Substituting from the home firm's first-order conditions into the expression for welfare change (5) and using the fact that $d y_{2}=\psi_{x} d x_{2}+\psi_{y} d y_{1}$ yields

$$
d W=-\left\{s_{1}+\rho R_{y}^{2} \frac{d y_{2}}{d x_{1}}+\rho x_{2} \Psi_{x}\right\} d x_{1}+R_{y}^{1} d y_{1}+\rho R_{y}^{2} \Psi_{y} d y_{1} .
$$


Solving for $s_{1}$, using $Y_{i 1}^{S}(i=1,2)$ to denote the response of $y_{i}$ to $x_{1}$ in this game, gives the expression for the first-period optimal subsidy in SE

$$
s_{1}^{S}=R_{y}^{1} Y_{11}^{S}+\rho R_{1}^{2} Y_{21}^{S}-\rho R_{y}^{2} \frac{d y_{2}}{d x_{1}}-\rho x_{2} \Psi_{x} .
$$

Here $Y_{21}^{S}=\psi_{y} Y_{11}^{S}: y_{2}$ responds to changes in $x_{1}$ only to the extent that the induced change in $y_{1}$ shifts the period-2 reaction function of the foreign firm. Comparing (25) with the optimal first-period subsidy in GCE (equation (15)), the new third effect is negative provided the second-period subsidy is a strategic complement for first-period output, conditions for which were given in Proposition 3. In that case the government has an additional incentive to tax the firm in period 1 relative to the profit-shifting benchmark: to restrain it from "overproducing" strategically in order to increase the subsidy it receives in period 2. Summarizing:

Proposition 4. In SE, the optimal period-2 subsidy is given by the standard Brander Spencer formula, reflecting intra-temporal rent-shifting only. The optimal period-1 subsidy, by contrast, includes rent-shifting terms (both intra- and inter-temporal) and a strategic term as in GCE. In addition, it includes a term which exactly offsets the home firm's strategic behaviour aimed at affecting the period-2 subsidy.

Since the three equilibria we have considered are different in general, the values of the three sets of optimal subsidies cannot be compared directly. What we have called the "rent-shifting benchmark" is different in each case, depending on the assumptions made about precommitment. In the next section we turn to consider two special cases where more definite results can be obtained.

\section{SPECIAL CASES}

\subsection{No foreign learning}

An important special case of the general model is where the foreign firm has already reached its mature phase, so its marginal costs are $c^{*}$ in both periods. ${ }^{11}$ This simplifies the model considerably. In each period, the foreign firm's reaction function depends on home output in that period only. Hence, the government's two policy instruments allow it to control all four targets in all three equilibria. The real equilibrium is the same in all cases, the only difference being the period-1 subsidy needed to attain it.

To see this formally, it may be confirmed from the previous three sections that, with no foreign learning, the rent-shifting components of the optimal subsidies in all cases collapse to $s_{i}^{F}=R_{y}^{i} Y_{i i}^{F}$. The additional strategic components exactly offset the strategic behaviour of the home firm. Hence, substituting these subsidies into the home firm's firstorder conditions gives an identical set of equations in all three equilibria

$$
\begin{aligned}
R_{1}^{1}-c_{1}+R_{y}^{1} Y_{11}^{r}+\rho \lambda x_{2} & =0, \\
R_{r}^{2}-c_{2}+R_{y}^{2} Y_{22}^{F} & =0 .
\end{aligned}
$$

11. Dasgupta and Stiglitz (1988) note that this asymmetric specification of learning seems to accord with most policy discussions of assistance to lcarning firms. 
These may be combined with the two first-order conditions for the foreign firm, which are also independent of the degree of commitment, since the foreign firm does not behave strategically. Hence the same four equations are solved for the four levels of output in all three games, so the solutions for outputs and welfare are identical. This in turn means that the subsidies may be ranked unambiguously. Summarizing:

Proposition 5. With no foreign learning, the levels of home and foreign output and welfare are the same in all three equilibria, irrespective of the degree of commitment; and the optimal subsidies may be ranked as follows

$$
s_{1}^{F}>s_{1}^{G}>s_{1}^{S} \text { and } s_{2}^{F}=s_{2}^{G}=s_{2}^{S} \text {, }
$$

where the first inequality holds if and only if $y_{2}$ is a strategic substitute for $x_{2}$ and the second holds if and only if $s_{2}^{S}$ is a strategic complement for $x_{1}$.

Finally, it is shown in the Appendix that the levels of output and welfare are increasing in the rate of learning.

\subsection{Linear demands and linear learning}

A different special case of the model is where both firms learn but the demand and learning functions are linear. This special case illustrates more forcefully some of the general results of previous sections and also allows us to examine explicitly the sensitivity of the different optimal subsidies to changes in the rate of learning and to explore the implications of relaxing other assumptions. In this sub-section, therefore, we assume that equations (1) and (2) are replaced by

$$
\begin{aligned}
& p_{i}=a-b\left(x_{i}+y_{i}\right), \quad i=1,2, \\
& c_{2}=c_{1}-\lambda x_{1}, \quad c_{2}^{*}=c_{1}^{*}-\lambda^{*} y_{1} .
\end{aligned}
$$

The first-order conditions under these assumptions are given in the first three columns of Table $1 .^{12}$ Solving these explicitly in the general case is not insightful. Instead, we illustrate the results diagrammatically and then give analytical expressions for the optimal subsidies in some special cases.

Figures 1 and 2 illustrate the optimal period-1 subsidies under our three assumptions about precommitment (assuming no discounting). The subsidies are shown as functions of parameters $\gamma$ and $\gamma^{*}$, defined as the home and foreign rates of learning normalized by the inverse demand slope (a measure of the market size): $\gamma \equiv \lambda / b$ and $\gamma^{*} \equiv \lambda^{*} / b{ }^{13}$ In both figures, when the foreign firm does not learn $\left(\gamma^{*}=0\right)$, the optimal period-1 subsidy is

12. Until Section 7.1, we continue to assume that the foreign government is passive. Hence, in the present section, the foreign subsidies $s_{1}^{*}$ and $s_{2}^{*}$ in Table 1 should be set equal to zero and the rows labelled $G_{1}^{*}$ and $G_{2}^{*}$ (which give the foreign government's first-order conditions) should be ignored.

13. Units of measurement in Figures 1,2 and 3 are chosen such that the optimal subsidy is unity in the static Brander-Spencer case of no learning $\left(\gamma=\gamma^{*}=0\right.$ ). (For reference, the optimal subsidy in that case equals $b x_{1} / 2$ or $\phi / 4 ; \phi$ equals $a-2 c_{1}+c_{1}^{*}$, a measure of the cost competitiveness of the home firm, and must be positive for an interior solution.) In Figures 1 to 4 we are only interested in values of $\gamma$ and $\gamma^{*}$ for which stability conditions are satisfied and all outputs are positive; otherwise the subsidies are arbitrarily set equal to zero. These restrictions become more demanding for high values of $\gamma$ and $\gamma^{*}$, all the more so if the home firm has an initial cost advantage which is why the scales are less in Figure 2. 


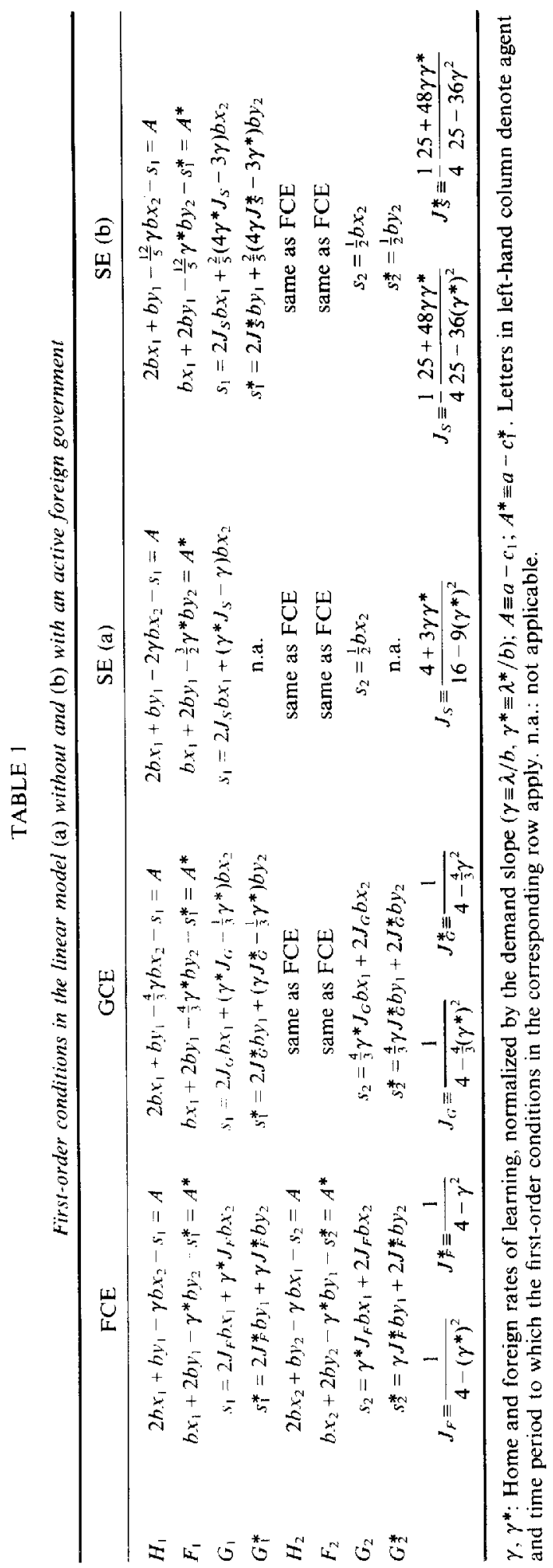


(i) FCE

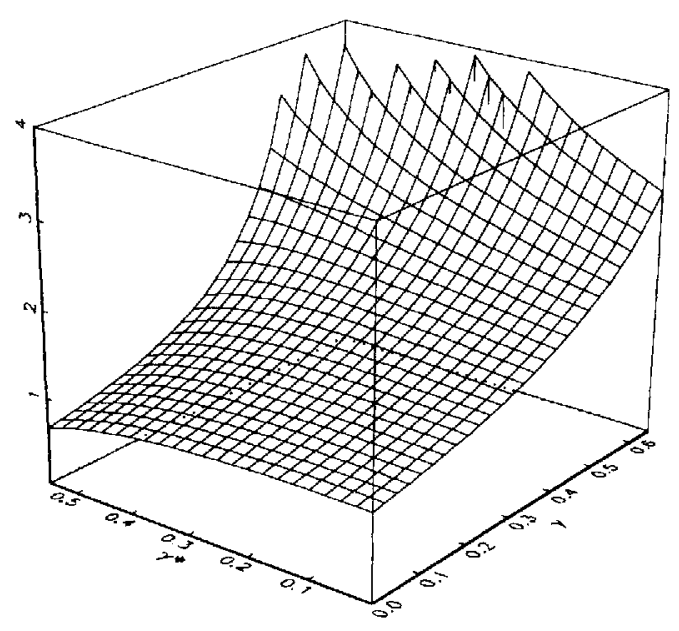

(ii) GCE

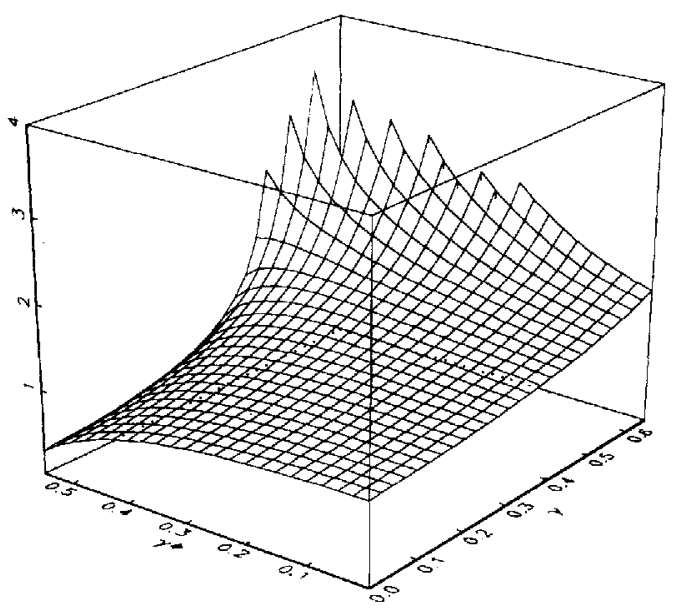

(iii) SE

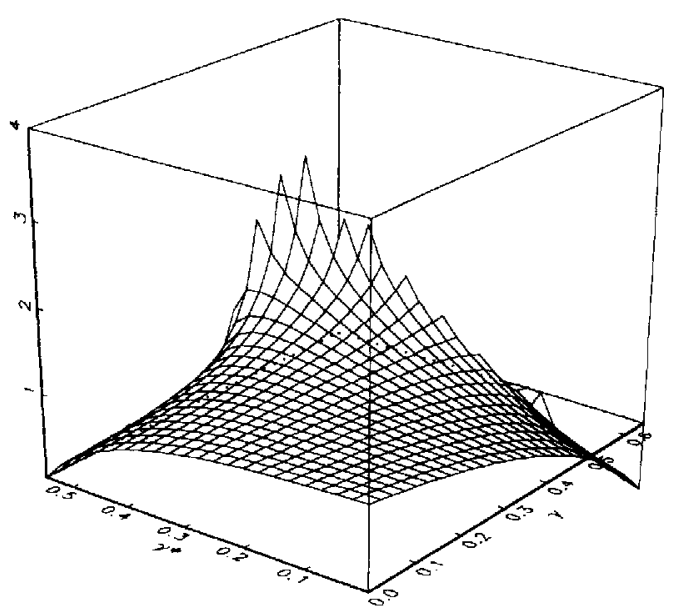

FIGURE 1

Optimal subsidy with learning by doing: $k=1 \cdot 3$

increasing in the home rate of learning $\gamma$ in both FCE and GCE but decreasing in it in SE. This result highlights the dramatic consequences of ruling out commitment.

When the foreign firm also benefits from learning, we must distinguish two cases, depending on which firm has a static (i.e. initial) cost advantage. Figure 1 illustrates the case where the foreign firm has a $30 \%$ initial cost advantage ${ }^{14}$ Here the period- 1 subsidy is decreasing in the foreign rate of learning in all cases (except when $\gamma$ is high) and, for given rates of learning, the subsidy is lower the lower the degree of precommitment. By contrast, both these conclusions are reversed in Figure 2, where the foreign firm has a $10 \%$ initial cost disadvantage. Thus, even in the simplest linear model, it is not true that the optimal subsidy is least when the government cannot precommit.

14. We measure this by the ratio $k \equiv A^{*} / A$, where $A \equiv\left(a-c_{1}\right)$ and $A^{*} \equiv\left(a-c_{1}^{*}\right)$. Hence $k=1+\left(c_{1}-c_{1}^{*}\right) / A$, which exceeds unity when the foreign firm has a cost advantage. 


\section{(i) $\mathrm{FCE}$}

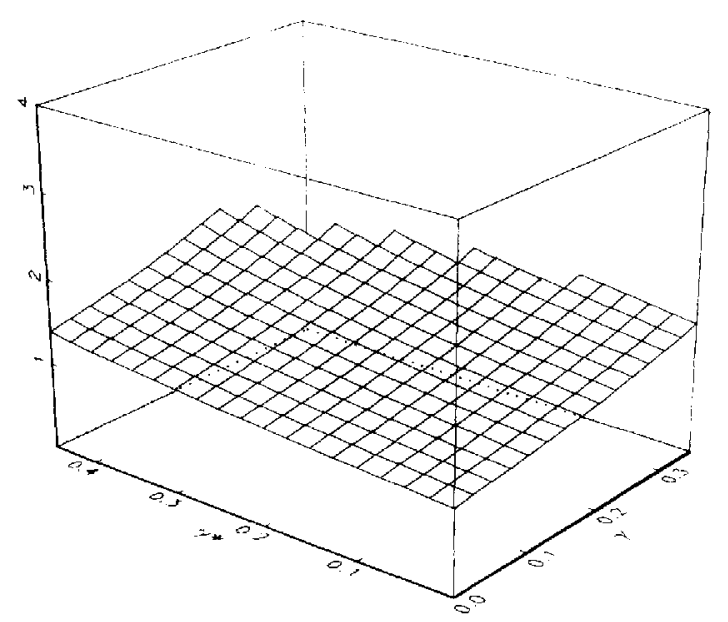

(ii) GCE

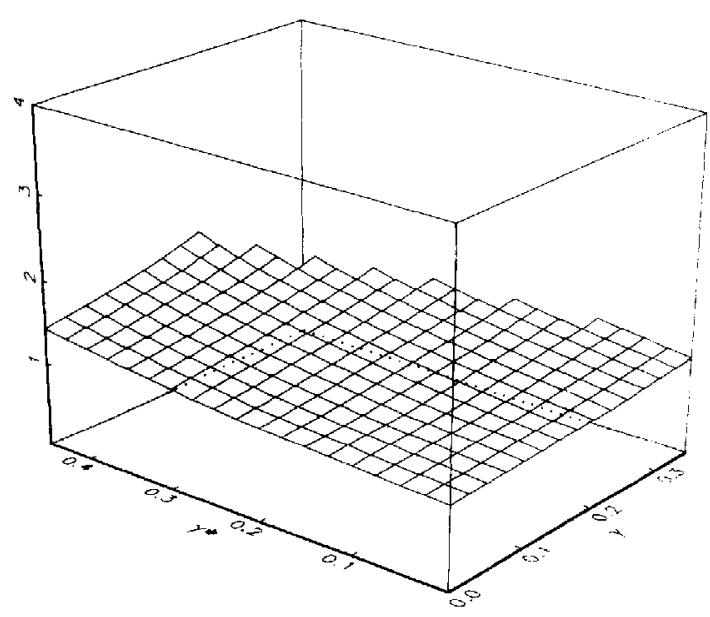

(iii) $\mathrm{SE}$

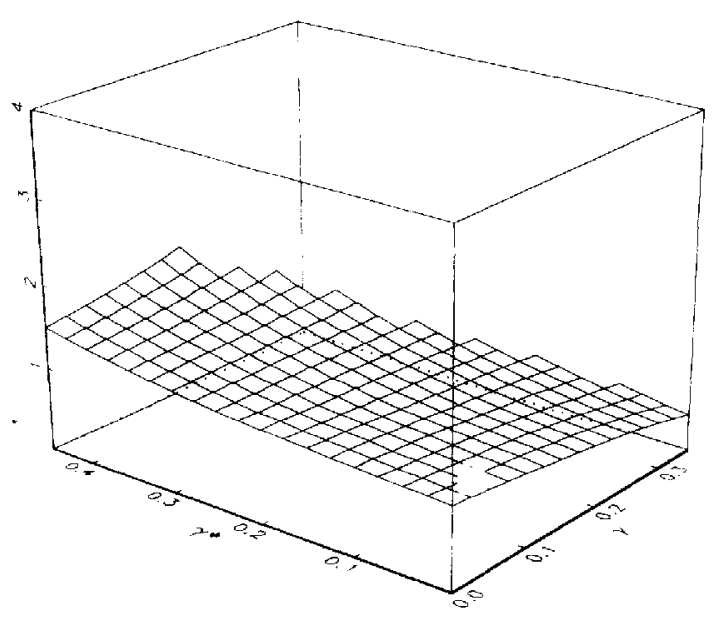

Figure 2

Optimal subsidy with learning by doing: $k=0.9$

To explore the robustness of some of these results we have calculated explicitly the optimal period-1 subsidies in each equilibrium under a variety of assumptions but assuming no foreign learning. The results are shown in the first four rows of Table $2 .{ }^{15}$ The first row gives the base case of zero discounting illustrated along the $\gamma^{*}=0$ axis in Figures 1 and 2. The next two rows relax in turn the assumptions of no discounting and of a single foreign firm. Finally, the fourth row relaxes the assumption of homogeneous products, replacing the demand function (29) by

$$
p_{i}=a-b\left(x_{i}+e y_{i}\right), \quad q_{i}=a-b\left(e x_{i}+y_{i}\right), \quad i=1,2 .
$$

15. The calculations underlying Table 2 are lengthy but straightforward. Some of the results are illustrated diagrammatically in Leahy and Neary (1994a and 1994b). Note an artefact of the linear specification: except in row 5, discussed in Section 7.2 below, the average of the FCE and SE subsidies equals the static BranderSpencer subsidy. 


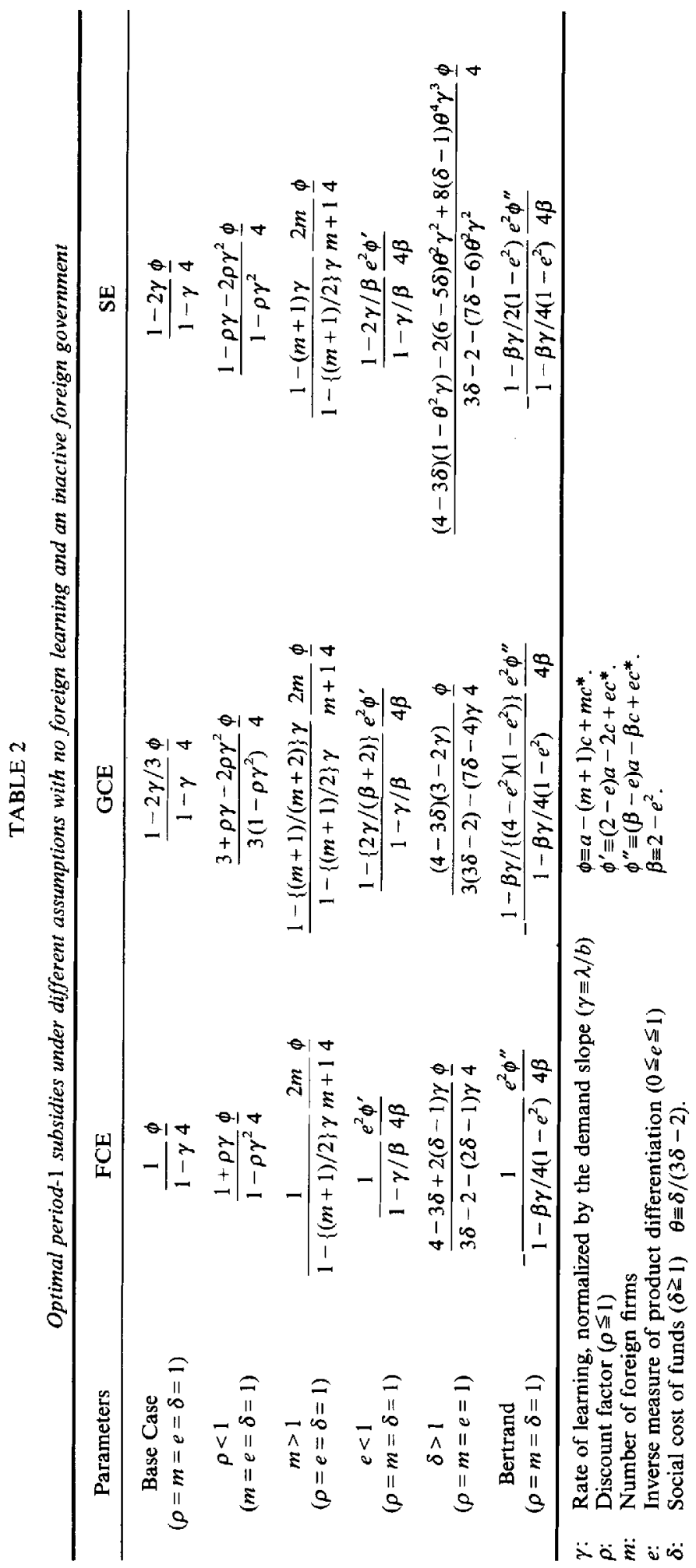


Here $p_{i}$ and $q_{i}$ are the prices of home and foreign output respectively and $e$ is an inverse measure of the degree of product differentiation.

A number of interesting results may be deduced from the first four rows of Table 2. The static optimal subsidy (corresponding to the case of no learning) is increasing in the number of foreign firms (as shown by Dixit (1984)) and decreasing in the degree of product differentiation. The responsiveness of the optimal subsidies to a higher rate of learning in all three equilibria falls as the future is discounted more heavily and as products are more differentiated; but it increases as the number of foreign firms rises. Finally, the most interesting feature from our point of view is that the results already noted for the base case continue to apply: the optimal subsidy is increasing in $\gamma$ in both FCE and GCE (less so in the latter) and decreasing in it in SE. Summarizing:

Proposition 6. With linear demands, linear home learning and no foreign learning, the optimal period-1 subsidy is increasing in the rate of learning if any intertemporal precommitment is possible. However, it is decreasing in the rate of learning in sequence equilibrium. This result is robust to relaxing the assumptions of no discounting, a single foreign firm and homogeneous products.

\section{EXTENSIONS}

\subsection{Active foreign government}

So far we have assumed that the foreign government is passive but this is clearly a special case. In particular, it prejudges the key question whether intervention is desirable. This must be so for unilateral intervention (though see Section 7.2 below) but it seems a priori unlikely if the rival government also intervenes optimally. To investigate this question, we need to consider the case where both governments are active.

A natural way to model the general case is to assume that, like firms, the governments move simultaneously, playing a Nash game in subsidies. Furthermore, in the absence of any compelling basis for asymmetry, it is natural to assume that both governments have the same powers of precommitment, whether complete (in FCE and GCE) or partial (in SE). Under these assumptions, all the equations derived in Sections 3 and 4 for the FCE and GCE cases are unchanged: both firms as well as the home government take foreign policy as given in making their decisions. Of course, these equations must be supplemented by the foreign government's two first-order conditions, which are identical in form to those of the home government.

Matters are more complicated in SE, since both government's period-2 subsidies are now subject to manipulation by both firms in period 1. Thus the foreign government's subsidy is determined by a reaction function, $s_{2}^{* s .}=\Psi^{*}\left(x_{1}, y_{1}\right)$, just like the home government's. The home firm's period-1 first-order condition (23) is unchanged, but the strategic effect $d y_{2} / d x_{1}$ is now even more complicated, since a change in $x_{1}$ has indirect effects on $y_{2}$ through both period-2 subsidies as well as a direct effect. Proceeding as in Section 5, the expression for the home period-1 optimal subsidy, (25), is unchanged and its interpretation is as before: the home government fully offsets the strategic behaviour by the home firm and uses its superior precommitment power to influence $y_{1}$ directly. However, the individual terms are more complex. For example $Y_{21}^{S}$ now equals $\left(\psi_{y}^{*}+\psi_{s} \Psi_{y}^{*}\right) Y_{11}^{s}$ : as before $y_{2}$ responds to changes in $x_{1}$ from the home government's perspective only to the extent that the induced change in $y_{1}$ shifts the period- 2 reaction function of the foreign 
firm; but now the reaction function is $y_{2}=\psi\left(x_{2} ; s_{2}^{*}, y_{1}\right)$, so this induced change has both a direct component and an indirect one, working through the effect of $y_{1}$ on $s_{2}^{*}$.

Table 1 illustrates these general points for the case of linear demand and learning functions. The columns headed FCE and GCE show that in these equilibria the equations are the same as in the case of a passive foreign government, except that they are supplemented by that government's policy variables, $s_{1}^{*}$ and $s_{2}^{*}$, and first-order conditions (labelled $G_{1}^{*}$ and $G_{2}^{*}$ ). By contrast, in SE, the period-1 equations are more complex (compare the columns headed "SE(a)" and "SE(b)"). Strategic effects are now stronger as each firm tries to manipulate both period-2 subsidies and each government intervenes to restrain its own firm. Figure 3 illustrates a typical configuration of optimal subsidies in the three equilibria (assuming the foreign firm has a $20 \%$ static cost advantage). (Note the

\section{(i) $\mathrm{F} C \mathrm{CE}$}

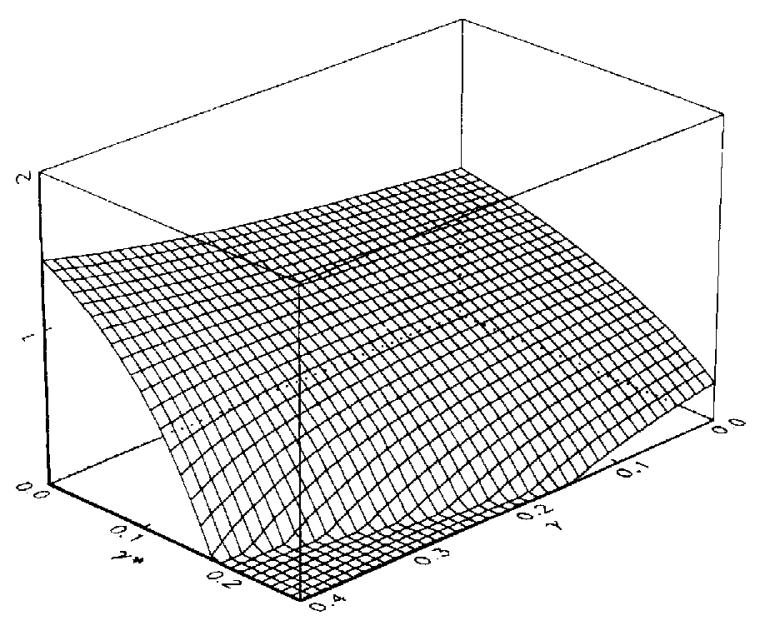

(ii) GCE

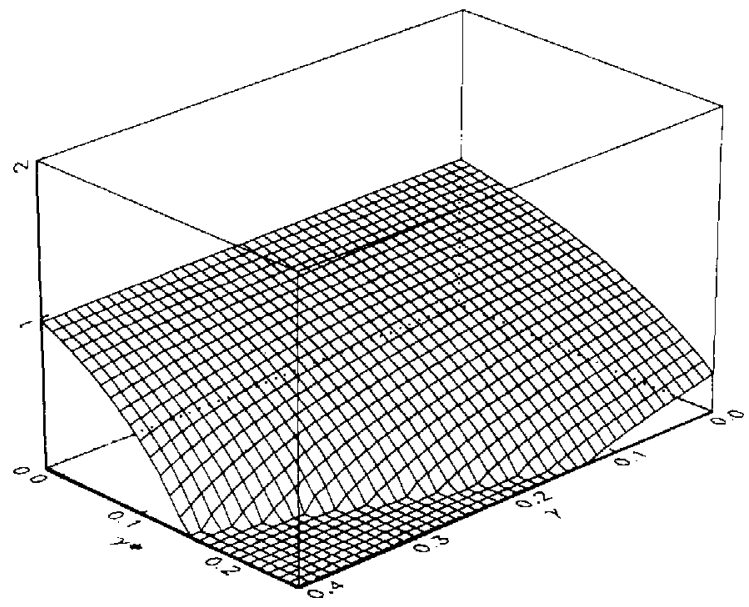

(iii) $\mathrm{SE}$

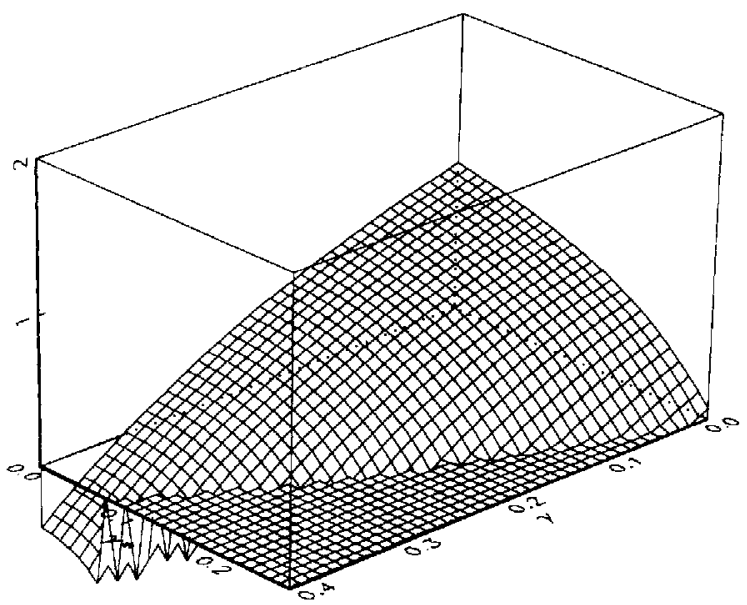

Figure 3

Optimal subsidy with active foreign government: $k=1 \cdot 2$ 
change of perspective from Figures $I$ and 2.) With both governments intervening the likelihood of one or other output level being forced to zero (in which case the optimal subsidy is set to zero) is greater, so the admissible range of $\gamma$ and $\gamma^{*}$ is less than in Figures 1 and 2 . But in other respects the qualitative implications are very similar to those in the case of a passive foreign government. ${ }^{16}$

Even more interesting than the optimal subsidies is whether welfare can rise in spite of foreign subsidization. As in Brander and Spencer (1985, Section 4), joint welfare of the two exporting countries would rise if subsidies were reduced from their Nash equilibrium levels. Nevertheless, Figure 4 shows that one country can gain if its firm has a sufficiently large cost advantage. The Figure gives the level of home welfare in SE when the foreign government is active relative to the corresponding level when firms behave strategically but both governments commit to free trade. (Similar results are found when the international subsidy games under FCE and GCE are compared with the corresponding freetrade equilibria.) Panel (i) shows that home welfare exceeds the free-trade benchmark when the home firm has both a static $(k<1)$ and a dynamic $\left(\gamma>\gamma^{*}\right)$ cost advantage. Panel (ii) shows that it may even gain in some extreme cases when the two firms have the same static efficiency $(k=1)$, provided the home firm has a sufficiently large dynamic advantage. However, home welfare is lower than in free trade in most cases, especially when the foreign firm has a static cost advantage, as in panel (iii). These findings are similar to those of Neary (1994): strategic trade policy is more likely to be successful the more costcompetitive is the home firm.

\subsection{Sensitivity to the social cost of funds}

We saw in Section 4 that the rationale for a corrective tax in GCE (relative to the profitshifting benchmark) was that the government could precommit to lower period-2 costs at zero social cost whereas the home firm could only precommit by overproducing inefficiently in period 1. Naturally, this argument is sensitive to the assumption that corporate profits have the same marginal social value as subsidy payments foregone; i.e. that the marginal social cost of funds is unity. On the other hand, if the social cost of funds exceeds unity, the rent-shifting argument for subsidization is weakened. To see how these contradictory influences interact, we follow Gruenspecht (1988) and Neary (1994) and use a parameter $\delta$ to measure the social cost of funds, so that the welfare function in each period becomes

$$
W_{i}=\pi_{i}-\delta s_{i} x_{i}=\left\{p_{i}-c_{i}-(\delta-1) s_{i}\right\} x_{i}, \quad i=1,2 .
$$

Proceeding as in Section 4, the change in welfare becomes

$$
d W=-\left(\delta s_{1}-\bar{s}_{1}^{G}\right) d x_{1}-(\delta-1) x_{1} d s_{1}-\rho\left(\delta s_{2}-\bar{s}_{2}^{G}\right) d x_{2}-\rho(\delta-1) x_{2} d s_{2} .
$$

Here $\bar{s}_{1}^{G}$ and $\bar{s}_{2}^{S}$ denote the formulae in (19) and (20) for the optimal GCE subsidies when the social cost of funds is unity. When this does not hold, we must relate the changes in home outputs directly to subsidy changes: $d x_{i}=X_{11} d s_{1}+X_{i 2} d s_{2}, i=1,2$, where the

16. It is possible to solve the FCE case analytically, making use of the fact that (with no discounting) the equilibrium is symmetric between periods. With no foreign learning $\left(\gamma^{*}=0\right)$, the responsiveness of $s_{1}$ to $\gamma$ is proportional to: $4\left(5-6 \gamma+2 \gamma^{2}\right) A-\left(15-16 \gamma+12 \gamma^{2}\right) A^{*}$. Assuming $\gamma<0.5$, this is positive for $k=1$ (i.e. $\left.A=A^{*}\right)$. However, for $k=4 / 3$, it is zero at $\gamma=0$ and negative thereafter (for $0<\gamma<0.5$ ). Thus, even in FCE, the optimal home subsidy may be decreasing in the home rate of learning with an active foreign government. 
(i) $k=0.9$

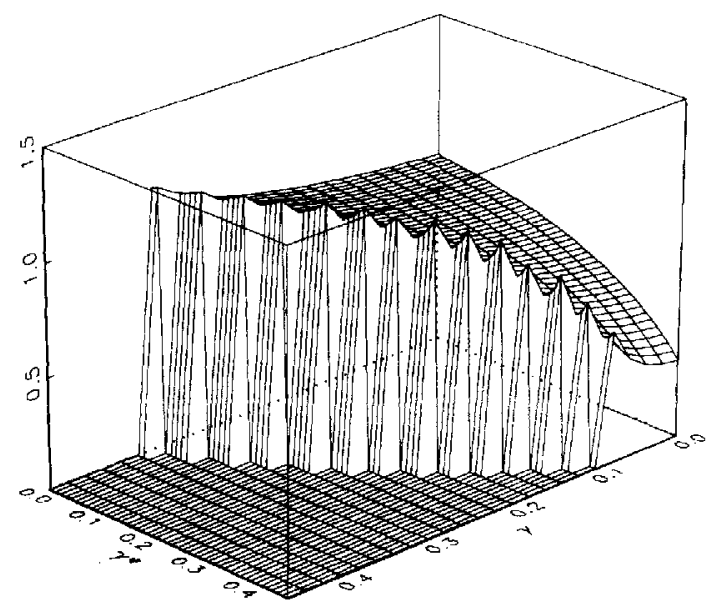

(ii) $\mathrm{k}=1.0$

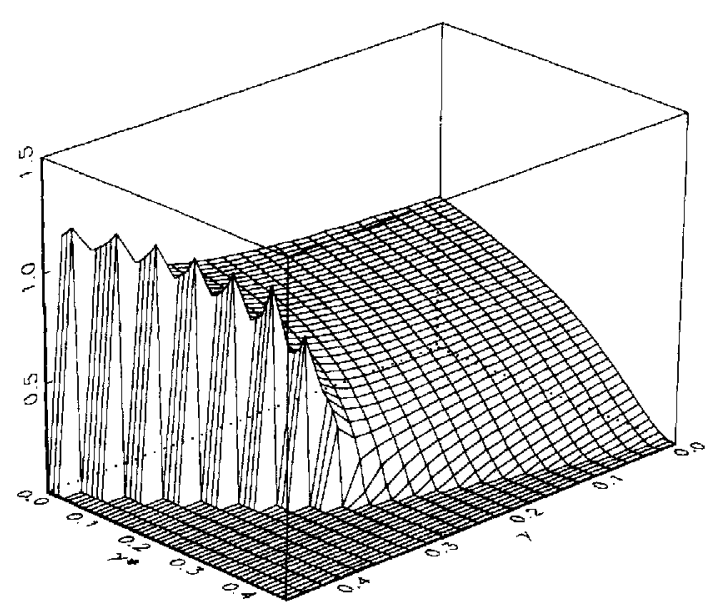

(iii) $\mathrm{k}=1.1$

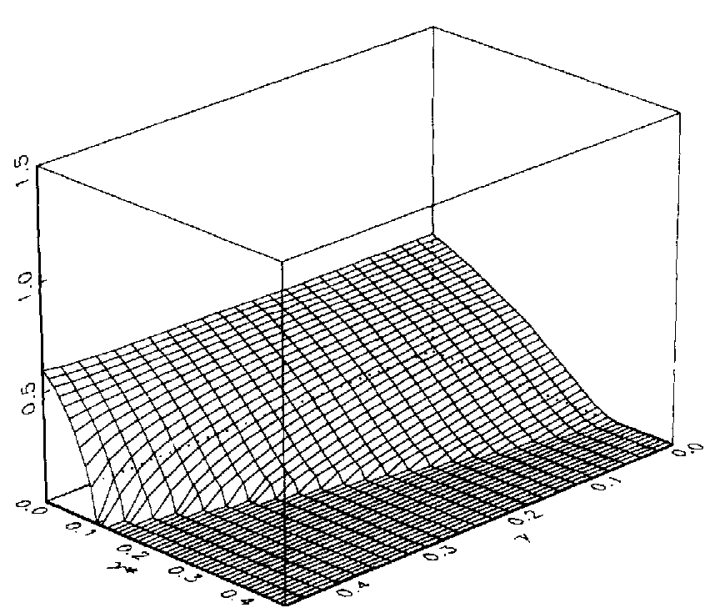

Figure 4

Home welfare in SE with an active foreign government relative to free trade

coefficients $X_{i j}$ are presumptively positive. Substituting into (33)

$$
s_{1}^{G}=\delta^{-1} \bar{s}_{1}^{G}-\delta^{-1}(\delta-1) \Delta_{x}^{-1}\left(x_{1} X_{22}-\rho x_{2} X_{21}\right),
$$

where $\Delta_{X}=X_{11} X_{22}-X_{12} X_{21}$ and is presumptively positive. This shows that both the rentshifting and strategic motives for intervention are diluted by higher values of $\delta$, while the final term representing the deadweight loss tends to encourage a tax and is more important the greater is $\delta$.

A different question related to the social cost of funds is raised by Proposition 5, which showed that in SE with no foreign learning the government can attain the same levels of output and welfare as with precommitment but with a lower period-1 subsidy. This immediately suggests that, if the social cost of funds exceeds unity, then welfare may 
be higher in SE than in equilibria with precommitment. ${ }^{17}$ Of course, this is not inevitable, since a change in the value of the social cost of funds changes all the optimal subsidies. To investigate this issue, differentiate the optimal level of welfare in each of the three equilibria and evaluate at $\delta=1$

$$
\left.\frac{d W^{h}}{d \delta}\right|_{\delta=1}=\left.\frac{\partial W^{h}}{\partial \delta}\right|_{\delta=1}=-\left(s_{1}^{h} x_{1}+\rho s_{2}^{h} x_{2}\right), \quad h=F, G, S
$$

This shows that, whether demands are linear or not, a small increase in $\delta$ starting at $\delta=$ 1 lowers welfare by the present value of total subsidy payments. Hence, from Proposition 5 , welfare falls more slowly with $\delta$ the lower the degree of precommitment when there is no foreign learning.

To see how this result applies when $\delta$ is strictly greater than unity, we have calculated the optimal period- 1 subsidies in each of the three equilibria assuming linear demands, linear home learning and no foreign learning. The results are given in the fifth row of Table 2 and their values in GCE and SE are illustrated in Figure 5. (The optimal subsidy in SE was derived in Neary (1994).) In both cases, a higher social cost of funds increases the incentive for the government to tax rather than to subsidize the firm, since the opportunity cost of subsidies is higher. In the absence of learning, the (normalized) optimal subsidy equals $(4-3 \delta) /(3 \delta-2)$, which falls from 1.0 towards -1.0 as $\delta$ rises. For low values of $\delta$, the optimal subsidies behave in the same way as in earlier cases: that in GCE increases in $\gamma$ while that in SE decreases in it. But as $\delta$ rises, both these relationships are reversed. In particular, the period-2 optimal subsidy in SE is proportional to $(4-3 \delta)$. Higher values of $\delta$ thus lead the home firm to anticipate a lower subsidy, or even (for $\delta$ greater than 4/3) a tax, next period, so reversing the negative relationship between $s_{1}^{s}$ and $\gamma$ which applies when $\delta$ is equal or close to unity.

Finally, Figure 6 illustrates the possibility that, because the period-1 subsidy is lower in SE than in GCE. welfare may be higher when the government cannot precommit and $\delta$ is greater than one. (Recall that welfare is the same in both equilibria when $\delta$ equals one.) The figure shows that this does not occur for high values of $\delta(e . g . \delta=2)$ but it does occur for values between 1.0 and $1 \cdot 2$. Because of the social cost of raising revenue, society may gain from the government's inability to precommit to future policies.

\subsection{Optimal policy in Bertrand competition}

The final case we consider is where firms compete on price rather than quantity. ${ }^{18}$ Eaton and Grossman (1986) have shown that this reverses the Brander-Spencer result in a one-period export-subsidy game: provided prices are strategic complements (the "normal" case in Bertrand competition), the optimal "profit-shifting" policy is an export tax rather than a subsidy. Similarly, from Fudenberg and Tirole (1984), the strategic incentive facing firms when period-2 prices are strategic complements is to behave like a "puppy dog" rather than a "top dog", underproducing in period 1 to raise prices and profits for both

17. In this paper we are only concerned with government precommitment to subsidy levels rather than to a subsidy rule. If the government could precommit to a second-period subsidy rule (a case for which a referee suggests the term "conditional commitment"), then it could always choose the rule implied by the sequence equilibrium and so always do at least as well as in the sequence equilibrium.

18. We confine attention to the cases where firms compete on either prices or quantity in both periods. An obvious extension is to the case considered by Kreps and Scheinkman (1983), where firms choose capacity outputs in the first period and prices in the second. However, this seems less appropriate in a learning-by-doing context, where periods should be thought of as years rather than weeks or months in length. 

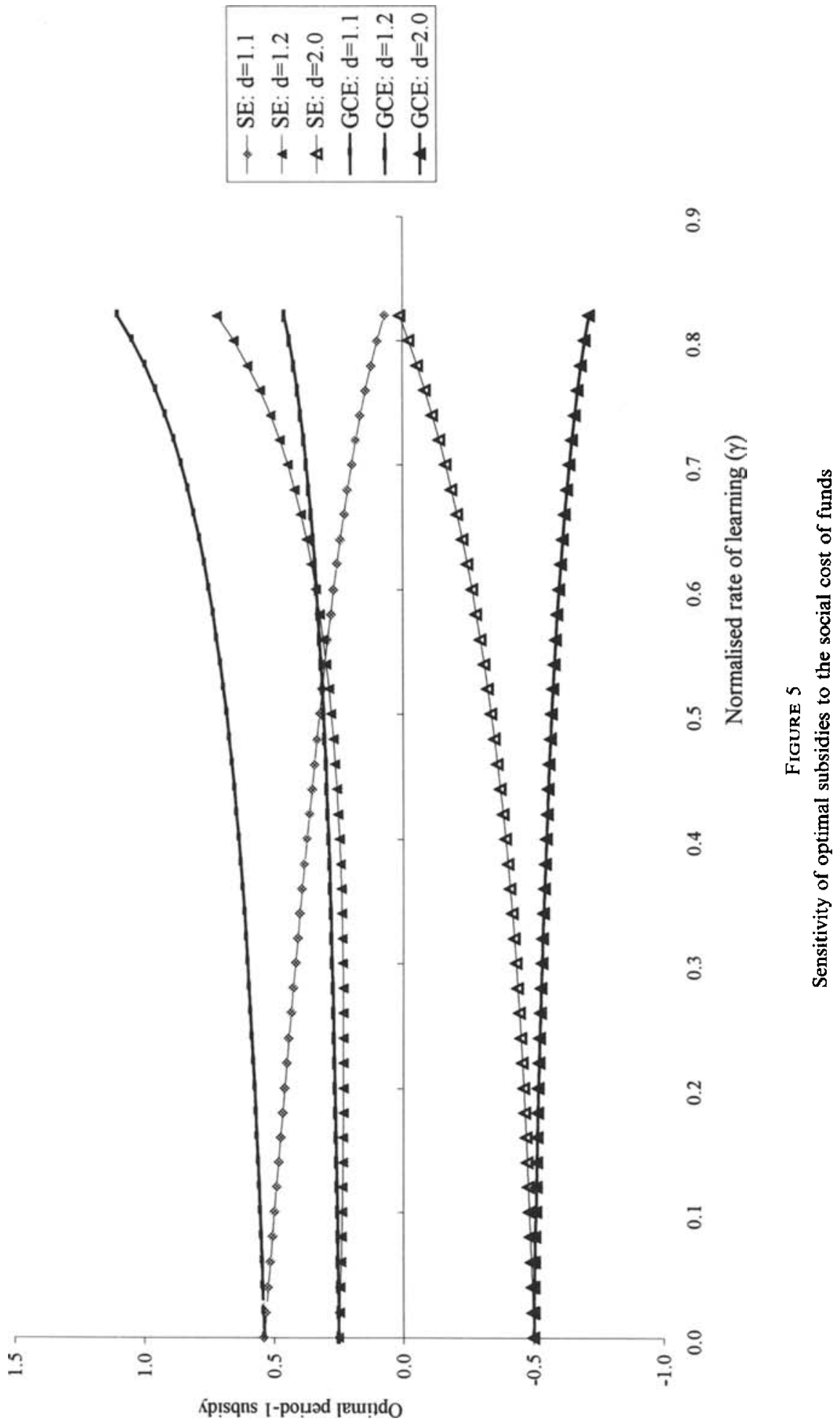


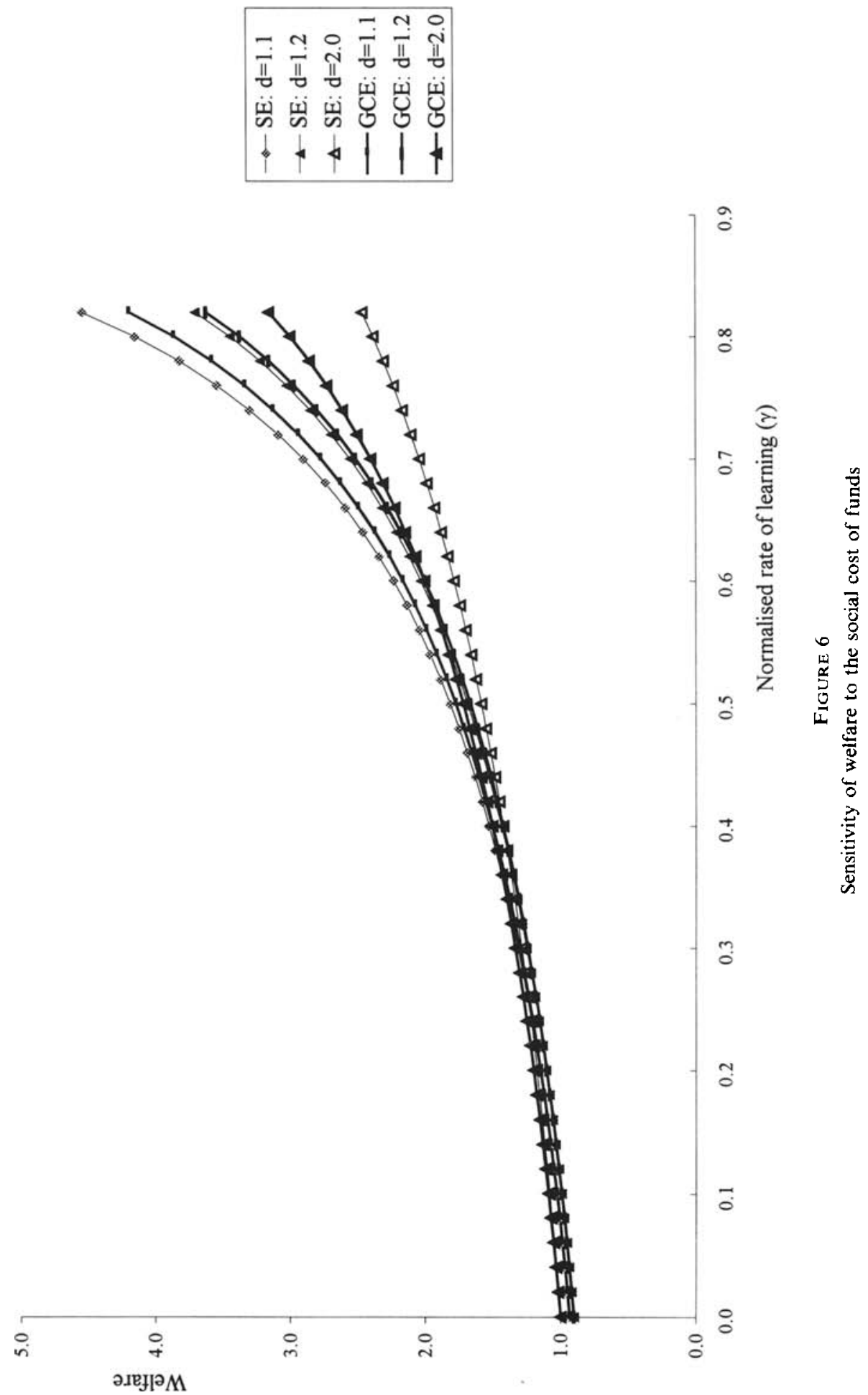


firms in period 2. Finally, since the period-2 policy is a tax whose absolute value is likely to be positively related to the home firm's cost competitiveness, the firm has an additional incentive to underproduce in SE. Hence, all three of the arguments for intervention given in Sections 3 to 5 are exactly reversed in Bertrand competition.

To illustrate these points, we have calculated the optimal period-1 subsidies when firms compete on price and demands are given by the linear, differentiated products specification, (31). The results are given in the final row of Table 2 and are illustrated (for different values of the product differentiation parameter $e$ ) in Figure $7 .^{19}$

The results in Figure 7 are very different from those in the Cournot quantity-competition case of previous sections. Now, the optimal subsidy is negative and decreasing in $\gamma$ in FCE but in SE it is increasing in $\gamma$ and, for high but plausible values of $\gamma$, it actually becomes positive. As for the optimal subsidy in GCE, it lies between those in FCE and $\mathrm{SE}$ and is increasing in $\gamma$, as in the Cournot case. These results reflect mechanisms similar to those explored in earlier sections. In FCE, there is no basis for government intervention other than that in the analysis of Eaton and Grossman: the government taxes the home firm in order to restrain it from competing too vigorously by keeping down its output price. This argument is not affected by higher rates of learning but the level of output is higher so the tax (which is positively related to output) rises too. In GCE, the home firm anticipates the future actions of its foreign rival and tends to raise its first-period price and so reduce its first-period output; this provides the government with a motive for subsidization which works against the Eaton-Grossman motive for taxation. Finally, in $\mathrm{SE}$, the firm anticipates that it will be taxed in the second period. In order to reduce the tax it will face, it has an incentive to raise price and so reduce output still further in the first, learning, period. Anticipating this tendency to "underproduce", the government counteracts it by offering a subsidy relative to the Eaton-Grossman benchmark. For sufficiently high values of $\gamma$, this motive for subsidization can outweigh the Eaton-Grossman motive for taxing. Once again, sequential decision-making by government tends to reverse the standard conclusions reached on the assumption that the government can precommit.

\section{SUMMARY AND CONCLUSIONS}

This paper has examined the implications for strategic trade policy of different assumptions about precommitment. We considered the choice of export subsidies in a dynamic oligopoly game with learning by doing. In general, and with surprisingly mild qualifications, we found that in Cournot competition strategic behaviour by firms which cannot precommit to future output justifies a first-period tax relative to the profit-shifting benchmark of a subsidy. Moreover, there is an additional argument for a first-period tax if the government cannot precommit to future subsidies. In the linear case the optimal period1 subsidy is increasing in the rate of learning with precommitment but decreasing in it if the government cannot precommit. Strategic considerations thus strengthen the infantindustry argument if the government can precommit to future subsidies but may reverse it in the absence of precommitment.

So far, we have remained neutral on which combination of assumptions about precommitment is most plausible in the context of learning by doing. It should be clear,

19. Following Eaton and Grossman, we assume throughout that products are sufficiently differentiated that an equilibrium in pure strategies exists. To facilitate reading the diagram, we have normalized the subsidies to equal minus one in the Eaton-Grossman case of no learning. 

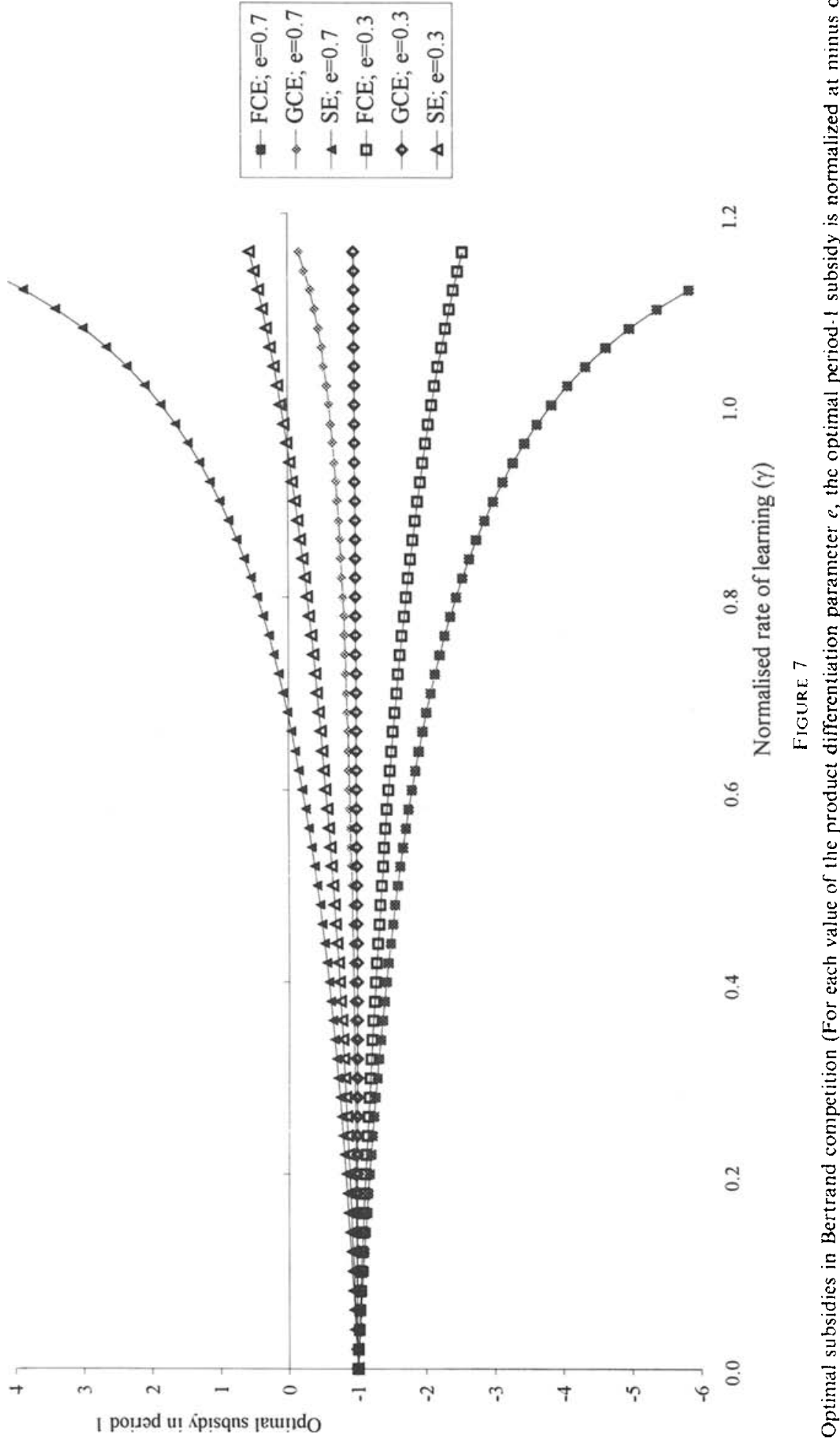
however, that we view the case which we have called "sequence equilibrium" as the most reasonable approximation of reality. This seems to us to be consistent with two stylized facts: on the one hand, governments are able to set subsidies which will remain in force for a period of weeks or months during which decisions on outputs will be made; on the other hand, they are unable to precommit to the subsidies which will prevail a few years ahead, when the firm has reached its mature phase. At the level of abstraction typically adopted in this literature, this seems a reasonable description of the legislative and administrative environment in which current policy decisions must be taken. Adopting this perspective suggests that the case for subsidizing exporting firms in high-technology industries may be weaker than is often thought.

It is instructive to compare our approach to the macroeconomics literature, where precommitment and time consistency have been much discussed since the work of Kydland and Prescott (1977). Macroeconomic theorists have devoted much attention to devising measures which would enable governments to precommit to future macroeconomic policies, such as constitutional amendments, conservative central banks or a social security system. The starting point for such analyses has been the fact that welfare is generally higher with government precommitment than without. By contrast, in our framework, welfare is independent of the assumptions made about precommitment if the foreign firm does not learn and, with a social cost of funds greater than unity, welfare may even be higher when precommitment is not possible.

Our model is far from being the last word on strategic trade policy with learning by doing. By ignoring exit and entry of firms, and assuming that learning is fully internalized by firms with no spillovers to rival firms at home or abroad, we have neglected many of the key issues in real-world policy discussions. The assumptions that firms compete in only one market and that learning ceases after one period are other features of our model which suggest that its specific policy conclusions should be interpreted with caution. All these extensions deserve to be explored and should be tractable in extended versions of the model we have considered.

A different set of issues raised by this paper concerns the relevance of our findings to other issues in microeconomics. Similar considerations apply to any area in which governments have an incentive to intervene in future periods and in which the extent of such intervention can be influenced by current private-sector actions. Applications to topics such as capacity choice, research and development, advertising and natural resources immediately suggest themselves. At a deeper level, our results suggest the need for a fundamental rethink of economic policy in dynamic environments. The fact that governments cannot precommit to future policies may mandate optimal intervention which is opposite in sign to the intervention which would be justified on the basis of a static model or (equivalently) a model in which government precommitment is possible. ${ }^{20}$

\section{APPENDIX}

\section{A1. Proof of Proposition 1.}

To calculate the slopes of the foreign firm's generalized reaction functions in FCE, totally differentiate its two first-order conditions (10) and (11)

$$
\begin{aligned}
\pi_{y_{1} y_{1}}^{*} d y_{1}+\pi_{y_{1} y_{2}}^{*} d y_{2}+\pi_{y_{1} x_{1}}^{*} d x_{1} & =0 \\
\lambda^{*} d y_{1}+R_{y y}^{* 2} d y_{2}+R_{y x}^{* 2} d x_{2} & =0
\end{aligned}
$$

20. For similar suggestions, see Hammond (1993). 
Note that $\pi_{y_{1} y_{1}}^{*}=R_{y y_{1}}^{* 1}+\rho y_{2} \lambda_{y}^{*} ; \pi_{y_{1}, y_{2}}^{*}=\rho \lambda^{*}$; and $\pi_{y_{1} x_{1}}^{*}=R_{y x}^{* 1}$. Solving these equations for $d y_{1}$ and $d y_{2}$ gives

$$
\begin{aligned}
& \Delta d y_{1}=-\pi_{y_{1} x_{1}}^{*} R_{y=}^{* 2} d x_{1}+\pi_{y_{1} y_{2}}^{*} R_{y x}^{* 2} d x_{2}, \\
& \Delta d y_{2}=\pi_{y_{1} x_{1}}^{*} \lambda^{*} d x_{1}-\pi_{y 1 y_{1}}^{*} R_{y x}^{* 2} d x_{2},
\end{aligned}
$$

where

$$
\Delta \equiv \pi_{y 1, n}^{*} R_{, y}^{* 2}-\pi_{* 1,2}^{*} \lambda^{*}
$$

From the foreign firm's second-order conditions, $\pi_{y_{1}, y_{3}}^{*}<0, R_{y, y}^{* 2}<0$ and $\Delta>0$. These yield the restrictions on the $Y_{i j}^{F}$ coefficients quoted in the text, recalling that $y_{i}$ is a strategic substitute for $x_{i}$ if and only if $\pi_{j, x_{i}}^{*}<0$.

\section{A2. Strategic Effects in GCE.}

To calculate the strategic effects in GCE, we totally differentiate the two firms' period-2 first-order conditions. The foreign firm's is given by (37) above, while the home firm's is obtained from (7)

$$
\lambda d x_{1}+R_{x x}^{2} d x_{2}+R_{x y}^{2} d y_{2}+d s_{2}=0 .
$$

Solving these for $d x_{2}$ and $d y_{2}$ gives

$$
\begin{aligned}
& \Delta_{2} d x_{2}=-R_{x y}^{* 2}\left(\lambda d x_{1}+d s_{2}\right)+R_{x y}^{2} \lambda^{*} d y_{1}, \\
& \Delta_{2} d y_{2}=-R_{x . x}^{2} \lambda^{*} d y_{1}+R_{y, \lambda}^{* 2}\left(\lambda d x_{1}+d s_{2}\right),
\end{aligned}
$$

where

$$
\Delta_{2} \equiv R_{x x}^{2} R_{y y}^{* 2}-R_{x y}^{2} R_{y x}^{* 2}
$$

Standard stability arguments require $\Delta_{2}$ to be positive while $R_{x x}^{2}$ and $R_{y y}^{* 2}$ are negative from the firms' secondorder conditions. Hence, the within-firm effects are unambiguous in sign and, as in Section A1, the betweenfirm effects depend on whether outputs are strategic substitutes for each other.

\section{A3. Optimal subsidies in GCE.}

The steps in deriving these are the same as in FCE, but with the additional complication that the foreign firm's period-1 first-order condition (17) depends on $s_{2}$ through the strategic term $d x_{2} / d y_{1}$. This adds an additional term $\pi_{y_{152}}^{*} d s_{2}=\rho R_{x}^{*^{2}}\left\{d^{2} x_{2} / d y_{1} d s_{2}\right\} d s_{2}$ to the left-hand side of (36); and the other coefficients in that equation must be reinterpreted (e.g. $\pi_{y_{1} x_{1}}^{*}$ becomes $R_{y x}^{* 1}+\rho R_{x}^{* 2}\left\{d^{2} x_{2} / d y_{1} d x_{1}\right\}$ ). Solving (36) and (37) with these amendments yields

$$
\begin{gathered}
d y_{1}=y_{11}^{G} d x_{1}+y_{12}^{G} d x_{2}+y_{1 s}^{G} d s_{2}, \\
y_{11}^{G i}=-\Delta^{-1} \pi_{y_{1} x_{1}}^{*} R_{y_{y}}^{*^{2}} \quad y_{12}^{G}=\Delta^{-1} \pi_{y_{1} y_{2}}^{*} R_{y x}^{* 2} y_{1 s}^{G}=-\Delta^{-1} R_{y y}^{* 2} \pi_{y_{1} s_{2}}^{*}, \\
d y_{2}=y_{21}^{G} d x_{1}+y_{22}^{G} d x_{2}+y_{2 x}^{G} d s_{2}, \\
y_{21}^{G}=\Delta^{-1} \pi_{y_{1} x_{1}}^{*} \lambda^{*} \quad y_{22}^{G}=-\Delta^{-1} \pi_{y_{1}, y_{1}}^{*} R_{y x}^{* 2} y_{2 s}^{G}=\Delta^{\prime} \lambda^{*} \pi_{y_{1} s_{2}}^{*} .
\end{gathered}
$$

The $y_{i j}^{G}$ coefficients can be signed exactly as the $Y_{i j}^{F}$ coefficients were in FCE; however, the signs of the $y_{i s}^{G}$ coefficients are indeterminate.

The next step is to substitute for $d y_{1}$ and $d y_{2}$ into the expression for welfare change, (18). The presence of terms in $d s_{2}$ makes it more complicated to solve this for the optimal subsidies than in FCE. Define coefficients $X_{i j}$, all presumptively positive, which give the total effects of changes in subsidies on home outputs: $d x_{i}=$ $X_{i 1} d s_{1}+X_{i 2} d s_{2}, i=1,2$. Substituting into (18) and solving for $s_{1}$ and $s_{2}$ yields equations (19) and (20), with the rent-shifting coefficients defined as follows

$$
\left[\begin{array}{ll}
Y_{11}^{G} & Y_{21}^{G} \\
Y_{12}^{G} & Y_{22}^{G}
\end{array}\right]=\left[\begin{array}{ll}
y_{11}^{G}-y_{1 s}^{G} X_{21} / \Delta_{X} & y_{21}^{C}-y_{2 s}^{G} X_{21} / \Delta_{X} \\
y_{12}^{G}+\rho y_{1 s}^{G} X_{11} / \Delta_{X} & y_{22}^{G}+\rho y_{2 s}^{G} X_{11} / \Delta_{X}
\end{array}\right]
$$

where $\Delta_{X}=X_{11} X_{22}-X_{12} X_{21}$. Given the complexity of these expressions they cannot be signed unambiguously. However, it is reasonable to presume that the additional terms in $y_{i s}^{G}$ are unlikely to dominate, since they depend on the second-order issue of the effect of changes in $s_{2}$ on the foreign firm's strategic term $d x_{2} / d y_{1}$. For example, all these terms disappear in the case of linear demands.

\section{A4. Proof of Proposition 3.}

We seek an expression for $\Psi_{x}$, which gives the effect of a change in $x_{1}$ on $s_{2}^{s}$, the optimal period-2 subsidy in SE. Since the influence of $x_{1}$ works solely through $c_{2}\left(x_{1}\right)$, this is equivalent to finding the effect of an exogenous increase in the home firm's marginal cost on the optimal subsidy in a static Brander-Spencer export subsidy game. We need to solve the three period-2 first-order conditions: (7) for the home firm; (11) for the foreign firm; 
and (21) for the home government. However, an indirect approach is more insightful than an explicit solution.

First, solve the foreign firm's first-order condition for its reaction function, $y_{2}=\psi\left(x_{2} ; y_{1}\right)$; combining this with the home firm's first-order condition to get a reduced-form expression for home output (whose total differential is equation (42)), $\hat{x}_{2}\left(s_{2} ; x_{1}, y_{1}\right)$; and substitute $\psi\left(x_{2} ; y_{1}\right)$ for $y_{2}$ to get reduced-form expressions for welfare and the optimal subsidy

$$
\begin{aligned}
\hat{W}_{2}\left(x_{2} ; x_{1}, y_{1}\right) & =R^{2}\left[x_{2}, \psi\left(x_{2}, y_{1}\right)\right]-c_{2}\left(x_{1}\right) \cdot x_{2}, \\
\hat{s}_{2}\left(x_{2}, y_{1}\right) & =R_{y}^{2}\left[x_{2}, \psi\left(x_{2}, y_{1}\right)\right] \cdot \psi_{x}\left(x_{2}, y_{1}\right) .
\end{aligned}
$$

The government's first-order condition can now be written as follows

$$
\frac{\partial W_{2}}{\partial s_{2}}=\frac{\partial \hat{W}_{2}}{\partial x_{2}} \frac{\partial \hat{x}_{2}}{\partial s_{2}}=-\left\{s_{2}-\hat{s}_{2}\left(x_{2}, y_{1}\right)\right\} \frac{\partial \hat{x}_{2}}{\partial s_{2}} .
$$

Next, differentiate (50) with respect to $s_{2}$ and evaluate at $s_{2}=s_{2}^{S}$ to get the government's second-order condition

$$
\left.\frac{\partial^{2} W_{2}}{\partial s_{2}^{2}}\right|_{s_{2}=s \leqslant}=-\left\{1-\frac{\partial \hat{s}_{2}}{\partial x_{2}} \frac{\partial \hat{x}_{2}}{\partial s_{2}}\right\} \frac{\partial \hat{x}_{2}}{\partial s_{2}}<0
$$

From (42), $\partial \hat{x}_{2} / \partial s_{2}$ is positive. Hence, the expression in brackets must be positive for an interior maximum. This has a useful corollary, since direct calculation of the total effect of a change in $x_{1}$ on $x_{2}$, allowing for the induced change in $s_{2}^{S}$, yields

$$
\frac{d x_{2}}{d x_{1}}=\left\{1-\frac{\partial \hat{x}_{2}}{\partial s_{2}} \frac{\partial \hat{s}_{2}}{\partial x_{2}}\right\}^{-1} \frac{\partial \hat{x}_{2}}{\partial x_{1}}
$$

From (42), $\partial \hat{x}_{2} / \partial x_{1}$ is positive. Hence, from the second-order condition (51) it follows that the right-hand side of (52) is positive. Summarizing:

Lemma 1. A rise in period-1 output, which lowers period-2 costs, must raise period-2 output, whether or not we allow for the endogenous adjustment of the period-2 subsidy.

Next, differentiate (50) with respect to $s_{2}$ and evaluate at $s_{2}=s_{2}^{S}$.

$$
\left.\frac{\partial^{2} W_{2}}{\partial s_{2} \partial x_{1}}\right|_{s_{2}=x_{2}^{5}}=\left\{\frac{\partial \hat{s}_{2}}{\partial x_{2}} \frac{\partial \hat{x}_{2}}{\partial x_{1}}\right\} \frac{\partial \hat{x}_{2}}{\partial s_{2}} .
$$

Combining (51), (52) and (53)

$$
\Psi_{x}=-\frac{\partial^{2} W_{2}}{\partial s_{2} \partial x_{1}} / \frac{\partial^{2} W_{2}}{\partial s_{2}^{2}}=\frac{\partial \hat{s}_{2}}{\partial x_{2}} \frac{d x_{2}}{d x_{1}} .
$$

From Lemma $1, \Psi_{x}$ is positive if and only if $\partial \hat{s}_{2} / \partial x_{2}$ is positive. Differentiating (49) yields

$$
\frac{x_{2}}{s_{2}^{s}} \frac{\partial s_{2}}{\partial x_{2}}=1+\mu_{2}+\alpha_{2} r_{2}\left(1+\psi_{x}\right)
$$

This proves Proposition 3. Note finally that, from (52) and (55), the total effect of an increase in $x_{1}$ on $x_{2}$ is algebraically greater than the partial effect, $d x_{2} / d x_{1}>\partial \hat{x}_{2} / \partial x_{1}>0$, if and only if $s_{2}^{S}$ is a strategic complement for $x_{1}$.

A5. Outputs and welfare with no foreign learning.

To prove that outputs are increasing in the learning parameter $\varepsilon$, totally differentiate equations (26) and (27) to obtain

$$
\left[\begin{array}{cc}
\xi_{1}-b_{1} \psi_{1}^{\prime} \sigma_{1}+\rho x_{2} \lambda_{x} & \rho \lambda \\
\lambda & \xi_{2}-b_{2} \psi_{2}^{\prime} \sigma_{2}
\end{array}\right]\left[\begin{array}{l}
d x_{1} \\
d x_{2}
\end{array}\right]=\left[\begin{array}{c}
-\rho x_{2} \lambda_{\varepsilon} \\
c_{2 \varepsilon}
\end{array}\right] d \varepsilon
$$

Here $\xi_{i}$ is defined as $R_{x x}^{i}+R_{x y}^{i} \psi_{i}^{\prime}$ (where $\psi_{i}^{\prime}$ is the slope of the foreign firm's static reaction function in period $i$ ), which is negative; $\sigma_{i}$ is the elasticity of $s_{i}$ with respect to $x_{i}$ given by (55); and $c_{2 \varepsilon}$ is the derivative of $c_{2}$ with respect to $\varepsilon$. Since the government is in effect choosing $x_{1}$ and $x_{2}$ to maximize welfare, the second-order conditions are that the diagonal terms in the left-hand side coefficient matrix be negative and that the determinant of the matrix be positive. Calculating the changes in $x_{1}$ and $x_{2}$, making use of these properties and the fact that, from (2), $\lambda_{\varepsilon}>0$ and $c_{2 E}<0$ gives the desired result. Finally, differentiating the welfare function (4) and applying the envelope theorem 


$$
\frac{d W}{d \varepsilon}=\frac{\partial W}{\partial \varepsilon}=-\rho x_{2} c_{2 \varepsilon}>0
$$

Hence welfare is also increasing in the rate of learning.

Acknowledgements. For helpful discussions and comments, we are very grateful to Patrick Bolton, Ian Jewitt and two anonymous referees, to Peter Hammond and Tony Venables and to participants in ERWIT 94 in Castelgandolfo, EEA 94 in Prague, and seminars at Birmingham, Bristol, Exeter, EUI (Florence), LSE, Newcastle, Pompeu Fabra (Barcelona), Princeton and Sussex. The second author's work on this paper forms part of the International Economic Performance Programme of the Centre for Economic Performance at the London School of Economics, supported by the UK ESRC. An earlier version was circulated as CEPR Discussion Paper No. 980 in July 1994.

\section{REFERENCES}

ARROW, K. J. (1962), "The Economic Implications of Learning by Doing", Review of Economic Studies, 44, $131-144$.

BALDWIN, R. E. (1969), "The Case Against Infant-Industry Tariff Protection", Journal of Political Economy, $77,295-305$.

BALDWIN, R. E. and KRUGMAN, P. R. (1988), "Market Access and International Competition: A Simulation Study of 16K Random Access Memories", in R. Feenstra (ed.), Empirical Methods for International Trade (Cambridge: MIT Press).

BARDHAN, P. (1970) Economic Growth, Development and Foreign Trade (New York: John Wiley).

BOND, E. W. (1993), "Capital Market Imperfections and the Infant-Industry Argument for Protection", in W. J. Ethier, E. Helpman and J. P. Neary (eds.). Theory, Policy and Dynamics in International Trade: Essays in Honor of Ronald $W$. Jones (Cambridge: Cambridge University Press), 191-212.

BRANDER, J. A. and SPENCER, B. J. (1985), "Export Subsidies and International Market Share Rivalry", Journal of International Economics, 18, 83-100.

BULOW, J. I., GEANAKOPLOS, J. D. and KLEMPERER, P. D. (1985), "Multimarket Oligopoly: Strategic Substitutes and Complements", Journal of Political Economy, 93, 488-511.

CARMICHAEL, C. M. (1987), "The Control of Export Credit Subsidies and its Welfare Consequences", Journal of International Economics, 23, 119.

CLEMHOUT, S. and WAN, H. Y. (1970), "Learning by Doing and Infant-Industry Protection", Review of Economic Studies, 37, 33-56.

DASGUPTA, P. and STIGLITZ, J. (1988), "Learning-by-Doing, Market Strueture and Industrial and Trade Policies", Oxford Economic Papers, 40, 246-268.

DE MEZA, D. (1986), "Export Subsidies and High Productivity: Cause or Effect?", Canadian Journal of Economics, 19, 347 . 350 .

DIXIT, A. (1980), "The Role of Investment in Entry Deterrence", Economic Journal, 90, 95-106.

DIXIT, A. (1984), "International Trade Policies for Oligopolistic Industries", Economic Journal (Supplement), 94, $1-16$.

EATON, J. and GROSSMAN, G. M. (1985), "Tariffs as Insurance: Optimal Commercial Policy when Domestic Markets are Incomplete", Canadian Journal of Economics, 18, 258-272.

EATON, J. and GROSSMAN, G. M. (1986), "Optimal Trade and Industrial Policy Under Oligopoly", Quarterly Journal of Economics, 101, 383.406.

FLAM, H. and STAIGER, R. W. (1991), "Adverse Selection in Credit Markets and Infant-Industry Protection", in E. Helpman and A. Razin (eds.), International Trade and Trade Policy (Cambridge: MIT Press), $96-117$.

FUDENBERG, D. and TIROLE, J. (1983), "Learning by Doing and Market Performance", Bell Journal of Economics, 14, 522-530.

FUDENBERG, D. and TIROLE, J. (1984), "The Fat-Cat Effect, the Puppy-Dog Ploy, and the Lean and Hungry Look", American Economic Review, Papers and Proceedings, 74, 361-366.

GATSIOS, K. (1989), "Imperfect Competition and International Trade", in F. H. Hahn (ed.), The Economics of Missing Markets, Information and Games, (Oxford: Oxford University Press), 188207.

GOLDBERG, P. K. (1995), "Strategic Export Promotion in the Absence of Government Precommitment", International Economic Review, 36, 407-426.

GROSSMAN, G. M. and HELPMAN, E. (1991), Innovation and Growth in the World Economy (Cambridge: MIT Press).

GROSSMAN, G. M. and HORN, H. (1988), "Infant-Industry Protection Reconsidered: The Case of Informational Barriers", Quarterly Journal of Economics, 103, 767-787.

GRUENSPECHT, H. (1988). "Export Subsidies for Differentiated Products", Journal of International Economics, 24, 331-344.

HAMMOND, P. J. (1993), "History as a Widespread Externality in Some Arrow-Debreu Market Games" (Discussion Paper No. 93/356, Department of Economics, University of Bristol). 
KREPS, D. M. and WILSON, R. (1982), "Sequential Equilibria", Econometrica, 50, 863-894.

KREPS, D. M. and SCHEINKMAN, J. A. (1983), "Quantity Precommitment and Bertrand Competition Yield Cournot Outcomes", Bell Journal of Economics, 14, 326-337.

KRUGMAN, P. R. (1984), "Import Protection as Export Promotion: International Competition in the Presence of Oligopoly and Economies of Scale", in H. Kierzkowski (ed.), Monopolistic Competition and International Trade (Oxford: Oxford University Press), 180-193.

KRUGMAN, P. R. (1987), "The Narrow Moving Band, the Dutch Disease and the Competitive Consequences of Mrs. Thatcher: Notes on Trade in the Presence of Dynamic Scale Economies", Journal of Development Economics, 27, 41-55.

KYDLAND, F. E. and PRESCOTT, E. C. (1977), "Rules Rather than Discretion: The Inconsistency of Optimal Plans", Journal of Political Economy, 85, 473-491.

LAPAN, H. E. (1988), "The Optimal Tariff, Production Lags, and Time Consistency", American Economic Review, 78, 395-401.

LEAHY, D. (1992), "Learning by Doing in International Subsidy Games" (Mimeo, University College Dublin).

LEAHY, D. and NEARY, J. P. (1994a), "Time Consistency, Learning by Doing and Infant Industry Protection: The Linear Case", Economic and Social Review, 26, 59-68.

LEAHY, D. and NEARY, J. P. (1994b), "Learning by Doing, Precommitment and Infant Industry Protection" (Discussion Paper No. 980, London: Centre for Economic Policy Research).

MASKIN, E. and NEWBERY, D. (1990), "Disadvantageous Oil Tariffs and Dynamic Consistency", American Economic Review, 80, 143-156.

MATSUYAMA, K. (1990), "Perfect Equilibria in a Trade Liberalisation Game", American Economic Review, 80, $480-492$.

NEARY, J. P. (1991), "Export Subsidies and Price Competition", in E. Helpman and A. Razin (eds.), International Trade and Trade Policy (Cambridge: MIT Press), 80-95.

NEARY, J. P. (1994), “Cost Asymmetries in International Subsidy Games: Should Governments Help Winners or Losers?", Journal of International Economics, 37, 197-218.

SELTEN, R. (1965), "Spieltheoretische Behandlung Eines Oligopolmodells Mit Nachfrageträgheit", Zeitschrift für die gesamte Staatswissenschaft, 12, 301-324.

SPENCE, M. (1977), "Entry, Capacity, Investment and Oligopolistic Pricing", Bell Journal of Economics, 8, $534-544$.

SPENCE, M. (1981), "The Learning Curve and Competition", Bell Journal of Economics, 12, 49-70.

SPENCER, B. J. and BRANDER, J. A. (1983), "International R\&D Rivalry and Industrial Strategy", Review of Economic Studies, 50, 707-722.

STAIGER, R. W. and TABELLINI, G. (1987), "Discretionary Trade Policy and Excessive Protection", American Economic Review, 77, 823-837.

VAN WIJNBERGEN, S. (1984), "The Dutch Disease: A Disease After All?", Economic Journal, 94, 41-55.

YOUNG, A. (1991), "Learning by Doing and the Dynamic Effects of International Trade", Quarterly Journal of Economics, 106, 369-406. 